\title{
Interannual variability of the Australian summer monsoon sustained through internal processes: wind-evaporation feedback, dynamical air-sea interaction and soil moisture memory
}

\author{
Shion Sekizawa, ${ }^{\text {a }}$ Hisashi Nakamura, ${ }^{\mathrm{a}}$ Yu Kosaka. ${ }^{\mathrm{a}}$ \\ ${ }^{a}$ Research Center for Advanced Science and Technology, the University of Tokyo, Tokyo, Japan
}

(Corresponding author: Shion Sekizawa, RCAST, the University of Tokyo, Japan.

E-mail: shion@atmos.rcast.u-tokyo.ac.jp)

\begin{abstract}
* This manuscript has been submitted for publication in Journal of Climate. It is not yet peer-reviewed. Subsequent versions of this manuscript may have slightly different content. If accepted, the final version of this manuscript will be available via a link on this webpage.
\end{abstract}

\begin{abstract}
In northern Australia (NAUS), mean rainfall during the Australian summer monsoon (AUSM) season exhibits distinct interannual variability despite weak influence from tropical sea surface temperature (SST) variability. The present study investigates mechanisms for the strong and persistent rainfall anomalies throughout the AUSM season. When the AUSM is stronger than normal, the low-level monsoonal circulation intensifies in response to the stronger convective activity over NAUS. The intensified surface westerlies over the tropical southeastern Indian Ocean (SEIO) enhance oceanic evaporation and downstream moisture transport into NAUS. This wind-evaporation feedback is verified through a moist static energy budget analysis. For this feedback to effectively work, SST cooling due to the stronger AUSM should be weak enough not to suppress the oceanic evaporation in the tropical SEIO. Our mixed-layer heat budget analysis based on an ocean model hindcast experiment reveals that anomalous downwelling in the subsurface SEIO, which is induced dynamically by the intensified monsoon westerlies, partially offsets the SST cooling. The land-surface evaporation over the continent is also enhanced significantly in the middle and later portions of the monsoon season associated with increased soil moisture and evaporation, suggesting the memory effect of soil for the persistency of rainfall anomalies. The AUSM variability can therefore be regarded as a selfsustaining internal variability in the atmosphere-ocean-land surface coupled system, rather than just an atmospheric internal variability.
\end{abstract}

\section{Introduction}

In austral summer, active convection around the Maritime Continent is concentrated in northern Australia (NAUS) in accordance with the southward migration of intense solar radiation into the Southern Hemisphere (Meehl 1987; Mitchell and Wallace 1992). Under the strong insolation, enhanced landsea thermal contrast forces low-level cyclonic (monsoonal) circulation, and associated moisture supply from the tropical southeastern Indian Ocean (SEIO) intensifies convective activity over NAUS, driving the Australian summer monsoon (AUSM; Suppiah 1992; Kawamura et al. 2002). Characterized as a period during which the trade easterlies are taken over by the monsoon westerlies, the AUSM typically onsets in late December and retreats in early March (Holland 1986; Hendon and Liebmann 1990a; Drosdowsky 1996; Kajikawa et al. 2010; Evans et al. 2014). We note that the AUSM is different from the NAUS rainfall season, which onsets earlier in austral spring when the land surface becomes wet enough to stimulate the plant growth (Lo et al. 2007). Since most of the annual rainfall in NAUS is brought about by the AUSM, the understanding, prediction and projection of AUSM rainfall variability are important for the agriculture and livestock industry in Australia (Mollah and Cook 1996; Bowman 2002; Howden et al. 2008). In addition, the AUSM variability remotely affects the 
climate in other regions of the globe. For instance, the anomalous AUSM modulates the strength of the East Asian winter monsoon, causing significant anomalies of temperature and precipitation over East Asia and the western North Pacific (Sekizawa et al. 2021).

Many studies have investigated links of the AUSM with tropical sea surface temperature (SST) variability as a major source of seasonal predictability. The monsoon tends to onset earlier during $\mathrm{La}$ Niña than during El Niño, while there is no significant change in the retreat date with regard to the phase of El Niño-Southern Oscillation (ENSO; Holland 1986; Drosdowsky 1996; Kajikawa et al. 2010; Evans et al. 2014). This implies a seasonal weakening of the impact of ENSO on AUSM from austral spring to summer. Indeed, seasonal-mean rainfall anomalies over NAUS are strongly correlated with ENSO in spring (pre-monsoon season) than in summer (Drosdowsky and Williams 1991; Risbey et al. 2009), even though ENSO peaks in austral summer (Larkin and Harrison 2002). Hendon et al. (2012) found that predictability for seasonal-mean NAUS rainfall becomes lower in austral summer than in spring, and attributed this predictability decrease to the reversal of the climatological-mean surface winds over the tropical SEIO. Under the prevailing trade easterlies in spring, enhanced NAUS convection can be supported through wind-evaporation-SST feedback (Xie and Philander 1994), where anomalous surface westerlies over the SEIO forced by the enhanced convection weaken the trade winds and thus reduce oceanic evaporation and mixing, acting to increase SST. By contrast, under the monsoonal westerlies in summer, anomalous westerlies instead intensify the surface winds, thus acting to decrease SST. In this manner, the atmospheric forcing on the ocean dominates in summer, and therefore the SST anomalies may no longer support persistent anomalous convection over NAUS.

Despite no support from local or remote SST anomalies, the summertime NAUS rainfall still exhibits pronounced interannual variability (Fig. 1a, solid blue line), as a manifestation of its dominant variability internal to the AUSM system. In the intraseasonal timescale, the influence of atmospheric internal perturbations, such as the Madden-Julian Oscillation (MJO) and midlatitude synoptic eddies, on the NAUS rainfall has been extensively documented (e.g., Hendon and Liebmann 1990b; Wheeler et al. 2009; Berry et al. 2011; Narsey et al. 2017). However, fundamental properties and mechanisms had been overlooked until recently for the internal interannual variability manifested as fluctuations of mean NAUS rainfall in the monsoon season. Sekizawa et al. (2018) revealed that January-February (JF)-mean NAUS rainfall anomalies are not a manifestation of modulated MJO events but that of the persistent rainfall anomalies throughout the AUSM season. They proposed that the AUSM variability can be sustained through a wind-evaporation feedback mechanism, where the intensified (weakened) monsoon westerlies due to enhanced (suppressed) NAUS convection act to enhance (suppress) the oceanic evaporation over the tropical SEIO and moisture transport into NAUS. This feedback mechanism works if SEIO SST cooling induced by the strong AUSM is weak enough to prevent the oceanic evaporation from being reduced. They also found that warm anomalies emerge below the mixed layer in the SEIO under the stronger AUSM, suggesting that the subsurface warm anomalies may play a role in damping the SST cooling. This effect has, however, remained to be verified quantitatively.

In addition to the wind-evaporation feedback mechanism, atmosphere-land surface interactions can also influence the AUSM rainfall variability. Sharmila and Hendon (2020) argued that positive

(a) Variance of rainfall (Total vs Internal)

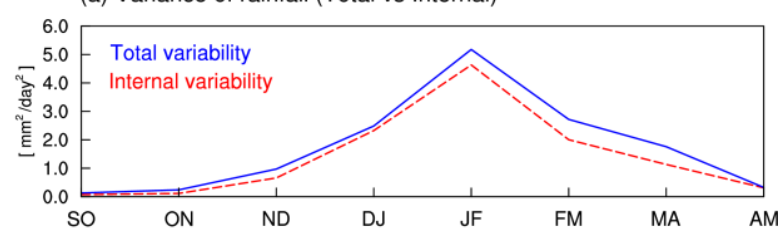

(b) Variance fraction of the internal variability

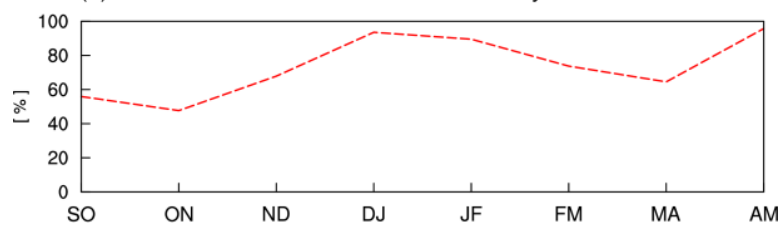

(c) 1-mon lag cor. of rainfall (Total vs Internal)

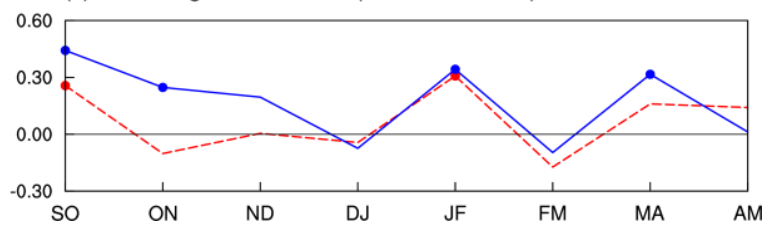

Fig. 1. (a) Interannual variance $\left(\mathrm{mm}^{2} \mathrm{day}^{-2}\right)$ of the total (solid blue line) and internal (dashed red line) component of bimonthly-mean NAUS rainfall averaged over the nine stations denoted in Fig. 2a. (b) Variance fraction (\%) of the internal variability to the total variability. (c) One-month lag correlation for the total (solid blue line) and internal (dashed red line) NAUS rainfall anomalies. Dots denote significant correlation at the $95 \%$ confidence level. See section 3a for estimation of the internal variability component. 
feedback between anomalous soil moisture and land-surface evaporation can sustain anomalous rainfall over NAUS, especially on decadal-tomultidecadal timescales. Martius et al. (2021) also examined atmospheric responses to anomalous soil moisture in the Australian Continent through a set of numerical model experiments and found that NAUS rainfall increases as a response to the anomalously wet land surface.

The aim of the present study is to deepen our understandings of the internal variability dominated in the AUSM system. Here, we verify that the windevaporation-convection feedback sustains the anomalous AUSM activity as pointed out by Sekizawa et al. (2018), in demonstrating that the wind-induced anomalous evaporation in the tropical SEIO is an essential source of anomalous moist static energy (MSE). We further quantitatively evaluate the damping effect of subsurface anomalies in the tropical SEIO on the SST anomalies, while investigating the effect of soil moisture for the persistency of the anomalous AUSM rainfall. Through these analyses, we attempt to reveal the nature of self-sustaining AUSM variability in the atmosphere-ocean-land surface coupled system, rather than just an atmospheric internal variability.

This paper is structured as follows. Section 2 describes datasets and analyses methods used in this study. In section 3, we examine the relationship between NAUS rainfall and tropical SST variability to confirm the domination of internal variability in the AUSM rainfall. Section 4 investigates mechanisms of persistent anomalous moisture supply into the convection anomalies over NAUS. The importance of wind-induced oceanic evaporation on sustaining the anomalous convection is verified through an MSE budget analysis, followed by a discussion on the potential role of soil moisture and land-surface evaporation. Section 5 assesses the role of dynamical air-sea interaction through a mixed-layer heat budget analysis based on a hindcast experiment with a high-resolution ocean general

(a) JF rainfall anom.
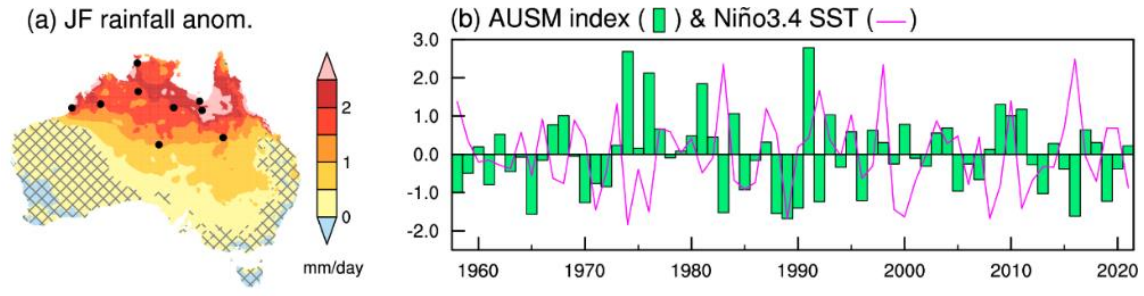

(c) SST anomaly (JF)

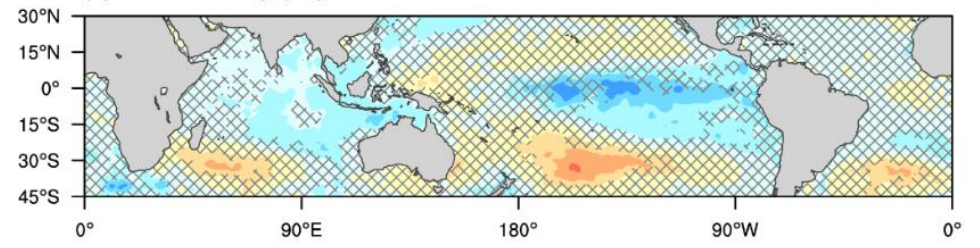

(d) SST anomaly (preceding SO)
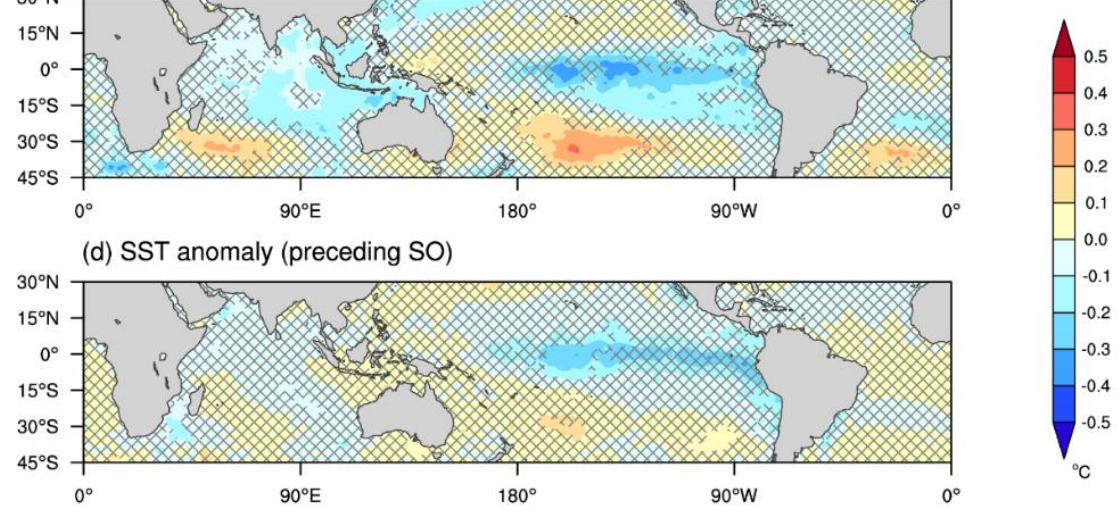

(e) Lag correlation with JF AUSM index

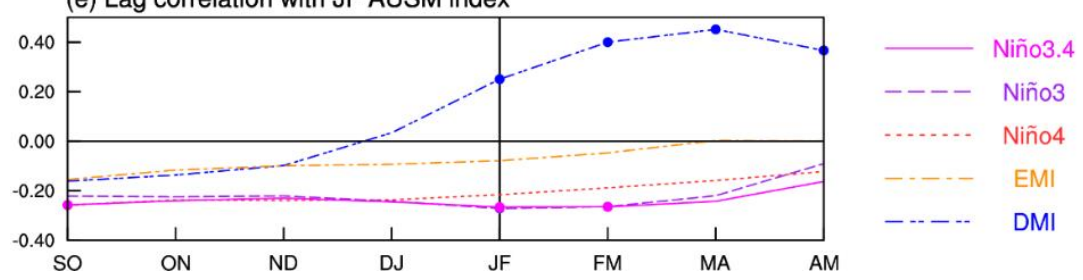

Fig. 2. (a) The nine stations used for defining our AUSM index (dots), and JF-mean rainfall anomalies based on AWAP (1958-2015) regressed onto the AUSM index (shading). (b) Standardized time series of the AUSM index (green bars) and Niño-3.4 SST (magenta line). (c) JF and (d) preceding September-October mean SST anomalies regressed onto the AUSM index. Areas with significance below the $95 \%$ confidence level are hatched in (a), (c) and (d). (e) Lagcorrelation coefficients of the AUSM index with various tropical SST indices. Dots denote significant correlations at the $95 \%$ confidence level. 
circulation model (OGCM). We provide a summary and discussion in section 6.

\section{Data and methods}

\section{a. Observational data}

We use rain gauge data for 1958-2021 obtained from the Australian Bureau of Meteorology. Following Sekizawa et al. (2018, 2021), JF-mean rainfall observed at the nine stations shown in Fig. $2 \mathrm{a}$ is averaged every year to define an AUSM index (Fig. 2b). Shading in Fig. 2a illustrates JF-mean rainfall anomalies based on the Australian Water Availability Project (AWAP) dataset with $0.05^{\circ} \times$ $0.05^{\circ}$ resolution (Jones et al. 2009) regressed onto the AUSM index for 1958-2015. Significant rainfall anomalies cover the entire NAUS and extend to its south in the middle of the continent, while rainfall anomalies in Western Australia and along the Pacific coast are insignificant. We also utilize evapotranspiration and soil moisture analyses for 19582019 from the Australian Water Resources Assessment system's landscape model (AWRA-L), which is a water balance model with horizontal resolution of $0.05^{\circ} \times 0.05^{\circ}$ driven by observed meteorological parameters (Frost et al. 2018). The soil moisture is provided separately for three layers; upper $(0-0.1 \mathrm{~m})$, lower $(0.1-1 \mathrm{~m})$ and deeper $(1-6$ $\mathrm{m})$ layers, and we integrate them over these layers for use in our analyses.

We use many other meteorological variables from the Japanese 55-year Reanalysis (JRA-55) of the global atmosphere produced by the Japan Meteorological Agency (Kobayashi et al. 2015), which has $1.25^{\circ} \times 1.25^{\circ}$ horizontal resolution and 37 isobaric levels available from 1958. JRA-55 provides three-dimensional diabatic heating fields separately as large-scale and convective condensation, radiative heating and vertical diffusion. We sum them up to use it as forcing to a linear baroclinic model (LBM) described later.

Hadley Centre Sea Ice and SST (HadISST) with resolution of $1^{\circ} \times 1^{\circ}$ (Rayner et al. 2003) is used for SST. This dataset is used for calculation of conventional tropical SST indices: Niño-3, Niño-3.4, Niño4, El Niño Modoki index (EMI; Ashok et al. 2007) and Indian Ocean dipole mode index (DMI; Saji et al. 1999), all of which are based on regionally averaged SST (see Fig. S1 for their definitions). We also use Ocean Reanalysis System 5 (ORA-S5) from the European Centre for Medium-Range Weather Forecasts (ECMWF) with horizontal resolution of $1^{\circ}$ $\times 1^{\circ}$ and 28 vertical levels within the upper $150 \mathrm{~m}$ (Zuo et al. 2019) for temperature and currents in the ocean. ORA-S5 provides five ensemble members with additional perturbations in forcing, observations and initial conditions. The ensemble mean fields are used in our analyses, but results do not change qualitatively if we use each of the ensemble members.

In the following, the analysis period varies depending on the dataset used, and thus we specify it in a figure caption or the text wherever necessary. Statistical significance of linear correlation and regression is assessed through the two-tailed $t$ test with degrees of freedom based on the number of sample years. A linear trend has been locally removed from any variable fields beforehand. The regressed anomalies are scaled to a unit standard deviation of the AUSM index.

\section{b. MSE budget analysis}

MSE is a thermodynamic variable that is virtually conserved in a moist adiabatic process. $\operatorname{MSE}(h)$ is represented as $h=c_{p} T+g z+L q$, where $T, z$ and $q$ denote air temperature, geopotential height and specific humidity, respectively, and constants $c_{p}$, $g$, and $L$ are the specific heat at constant pressure for air $\left(1004.6 \mathrm{~J} \mathrm{~K}^{-1} \mathrm{~kg}^{-1}\right)$, gravitational acceleration $\left(9.80665 \mathrm{~m} \mathrm{~s}^{-2}\right)$ and latent heat of vaporization for water $\left(2.507 \times 10^{6} \mathrm{~J} \mathrm{~kg}^{-1}\right)$, respectively. An equation for the column integrated MSE budget can be expressed as

$$
\begin{aligned}
\frac{\partial\langle h\rangle}{\partial t} & =-\langle\boldsymbol{u} \cdot \nabla h\rangle-\left\langle\omega \frac{\partial h}{\partial p}\right\rangle+L E+S+\langle R\rangle \\
& =-\nabla \cdot\langle\boldsymbol{u} h\rangle+Q
\end{aligned}
$$

where $\boldsymbol{u}, \omega, E, S$ and $R$ indicate horizontal wind vector, vertical pressure velocity, surface evaporation, surface sensible heat flux and radiative heating rate, respectively (Yanai et al. 1973). Angle brackets denote column integration from the surface to the 100-hPa level. Combining MSE sources into the atmosphere aside from the MSE flux convergence, $Q=L E+S+\langle R\rangle$ is referred to as an MSE forcing.

The MSE flux convergence consists of horizontal and vertical advection terms assuming the vertical flux to be zero at the top of the column. Since the weak temperature gradient approximation usually holds in the tropical troposphere, a strong horizontal gradient of MSE arises mainly from that of humidity in the lower troposphere. Considering that an atmospheric column with lower-level convergence is wetter than the surroundings as a usual situation in active convection, horizontal advection by the incoming flow acts to decrease the column-integrated MSE. Meanwhile, the vertical 
advection depends on the correspondence between the vertical profiles of MSE and divergence. When the MSE at the level of convergence is larger (smaller) than that at the level of divergence, the column-integrated MSE increases (decreases). Since MSE is usually larger in the upper troposphere than near the surface, a deep convective activity discharges MSE out of the column through the vertical advection. However, under the condition that the near-surface air is so wet that the MSE difference between the upper and lower troposphere is small, the vertical advection cannot efficiently discharge MSE from the column (Neelin and Held 1987).

Although precipitation does not appear explicitly in Eq. (1), it can be diagnosed through the MSE and moisture budgets. Combining the columnintegrated MSE and moisture budget equations and supposing a steady state, we obtain

$$
\begin{aligned}
L(P-E)= & \frac{Q}{\Gamma}, \\
& \text { where } \Gamma \equiv \frac{\nabla \cdot\langle\boldsymbol{u} h\rangle}{-L \nabla \cdot\langle\boldsymbol{u} q\rangle} .
\end{aligned}
$$

When precipitation is much larger than evaporation, as typically is the case in a region of active convection, $P-E \approx P$. Thus, precipitation can be given by the local MSE forcing $Q$ divided by normalized gross moist stability (GMS) $\Gamma$. The normalized GMS represents the efficiency for the circulation to discharge MSE out of the column by convection of unit intensity (Neelin and Held 1987; Raymond et al. 2009; Inoue and Back 2015), and it can be decomposed into the horizontal and vertical components as

$$
\begin{aligned}
\Gamma & =\Gamma_{h}+\Gamma_{v} \\
& =\frac{\langle\boldsymbol{u} \cdot \nabla h\rangle}{-L \nabla \cdot\langle\boldsymbol{u} q\rangle}+\frac{\left\langle\omega \frac{\partial h}{\partial p}\right\rangle}{-L \nabla \cdot\langle\boldsymbol{u} q\rangle} .
\end{aligned}
$$

The vertical GMS $\Gamma_{v}$ indicates the efficiency for the divergence and convergence to discharge MSE through vertical advection, which is related to the vertical profile of MSE, i.e., the vertical stability (corresponding to the original concept of GMS by Neelin and Held 1987). Likewise, the horizontal GMS $\Gamma_{h}$ represents the efficiency of discharging MSE due to horizontal advection under the horizontal MSE gradient between the region of interest and its surroundings.

In this study, we have performed the MSE budget analysis for JF-mean MSE anomalies regressed onto the AUSM index based on 6-hourly data from JRA-55 (1958-2021). We have confirmed that the results do not change qualitatively if the analysis is limited to the period after 1979. Any anomalies correlated with Niño-3.4 SST have been removed, in order to emphasize a feature of internal AUSM variability.

\section{c. OGCM output and mixed-layer heat budget analysis}

In our attempt to perform a mixed layer heat budget analysis to evaluate the effect of the subsurface anomalies, ocean data with higher spatiotemporal resolution is required to obtain quantitatively reliable results. For this purpose, we analyze the output from a hindcast simulation by an eddy-resolving OGCM for the Earth Simulator (OFES) for 1980-2014 (Sasaki et al. 2008). The model has a horizontal resolution of $0.1^{\circ} \times 0.1^{\circ}$ and 54 vertical levels with 5 to $10-\mathrm{m}$ thickness in upper $200 \mathrm{~m}$, being forced by daily mean momentum, heat and salinity fluxes taken from the National Centers for Environmental Prediction (NCEP) and the National Center for Atmospheric Research (NCAR) atmospheric reanalysis (Kalnay et al. 1996). In the output, fields of temperature, salinity, 3-dimensional velocity, surface fluxes are available every 3 days, and therefore the OFES output is better suited for the following mixed-layer heat budget analysis. Note that the surface salinity field is relaxed to monthly climatology in this simulation.

Following a formulation for the ocean mixedlayer heat budget proposed by Kim et al. (2006), a time tendency of the mixed-layer temperature $T_{m}$, i.e., vertically averaged temperature within the mixed layer, can be expressed as

$$
\begin{gathered}
\frac{\partial T_{m}}{\partial t}=\frac{Q_{n e t}-q_{S W}}{\rho_{w} c_{w} h_{m}}-[\boldsymbol{u} \cdot \nabla T]_{M L}-[\boldsymbol{u} \cdot \nabla T]_{I N D} \\
-\left[w \frac{\partial T}{\partial z}\right]-\frac{\partial h_{m}}{\partial t} \frac{\Delta T}{h_{m}}
\end{gathered}
$$

We have defined the mixed-layer depth $h_{m}$ at which temperature is lower than SST by $0.8^{\circ} \mathrm{C}$, following Du et al. (2005). Overall results do not qualitatively change if we use the threshold of $0.5^{\circ} \mathrm{C}$ instead of $0.8^{\circ} \mathrm{C}$ for the definition. The first term on the rhs in Eq. (4) represents heating by the net surface heat fluxes $Q_{n e t}$, where water density $\rho_{w}\left(=1027 \mathrm{~kg} \mathrm{~m}^{-3}\right)$ and specific heat for water $c_{w}\left(=4187 \mathrm{~J} \mathrm{~K}^{-1} \mathrm{~kg}^{-1}\right)$ are assumed to be constant. In addition, $q_{S W}$ indicates shortwave radiation penetrating into subsurface layers, which is estimated through the same parameterization as used in OFES: 


$$
q_{S W}=Q_{S W}\left\{R e^{-\frac{h_{m}}{\xi_{1}}}+(1-R) e^{-\frac{h_{m}}{\xi_{2}}}\right\},
$$

where $Q_{S W}$ is the net downward surface shortwave radiation, and the parameters $R, \xi_{1}$ and $\xi_{2}$ are set to $0.58,0.35 \mathrm{~m}$ and $23 \mathrm{~m}$, respectively (Paulson and Simpson 1977). The second term of rhs in Eq. (4) represents the horizontal temperature advection vertically averaged within the mixed layer, where $\boldsymbol{u}$ and $T$ are horizontal velocity and temperature, respectively. The third through fifth terms represent the entrainment as combined. The third term indicates the horizontal induction, due to horizontal temperature advection across the inclined mixed layer bottom, which is usually small in the maritime domain of our interest. The fourth term denotes the vertical temperature advection averaged within the mixed layer, including the effect of shoaling (deepening) isothermal surfaces due to the upwelling (downwelling). Here, the square bracket signifies vertical averaging within the mixed layer. The fifth term is related to the mixed-layer deepening and the associated entrainment of cooler water from below. $\Delta T$ is locally derived as the difference of vertically averaged temperature between the water remaining in the mixed layer at both the present and next time steps and another water to be entrained or detrained at the next time step.

As in the MSE budget analysis, we have evaluated the mixed-layer heat budget for JF-mean anomalies regressed onto the AUSM index. Any anomalies correlated with Niño-3.4 SST have been removed, in order to emphasize a feature of internal AUSM variability.

\section{d. Linear baroclinic model (LBM)}

To examine the local wind response to anomalous diabatic heating over NAUS, we conducted numerical experiments with an LBM developed by Watanabe and Kimoto (2000). This primitive equation model is linearized about a prescribed three-dimensional basic state and simulates the dry dynamical response to imposed diabatic heating. The model has horizontal and vertical resolutions of T42 and 20 levels in $\sigma$ coordinates, respectively, with biharmonic diffusion of $e$-folding time of 1 hour for the largest wavenumber and vertical diffusion of $e$-folding time of 1000 days. We also apply linear damping with $e$ folding time of 0.5 days in $\sigma \geq 0.945$ and $\sigma \leq 0.025$, 5 days at $\sigma=0.900,15$ days at $\sigma=0.830$ and 30 days in $0.035 \leq \sigma \leq 0.745$. We prescribe the JF-mean climatological mean field as a basic state of the LBM and forced it by the JF-mean anomalies of diabatic heating rate over NAUS $\left(30^{\circ}-5^{\circ} \mathrm{S}, 105^{\circ}-165^{\circ} \mathrm{E}\right)$ regressed onto the AUSM index, both of which has been derived from JRA-55 (1958-2019). Here, we regard the average of the response from the 31 st to 45 th days of the integration as the steady response.

\section{Properties of interannual variability of NAUS rainfall}

\section{a. Relation to the tropical SST variabilities}

Consistent with the previous studies, the AUSM variability has relatively weak linkage to the tropical SST anomalies. Figures $2 \mathrm{c}$ and $2 \mathrm{~d}$ represent JF and September-October (SO)-mean SST anomalies, respectively, regressed onto the JF-mean AUSM index. A typical La Niña and Indian Ocean basinwide cooling signatures develop, but its amplitude and statistical significance are moderate. Indeed, the correlation coefficient between the JF-mean AUSM index and the Niño-3.4 index is -0.26 , which is marginally significant at the $95 \%$ confidence level but explains only $\sim 7 \%$ of the variance. At the same time, a cool SST anomaly is conspicuous locally around NAUS in JF, under the enhanced evaporation and less insolation as responses to the stronger AUSM (section 5), indicating the dominance of atmospheric forcing to the ocean. We cannot see any organized SST anomalies associated with IOD in austral spring, which is known to exert a significant impact on Australian rainfall (Ashok et al. 2003; Risbey et al. 2009; Cai et al. 2011).

Figure 2e shows lag-correlation coefficients of various tropical SST indices with the JF-mean AUSM index. Consistent with the spatial pattern of SST anomalies as illustrated in Fig. 2c and 2d, the correlations are generally weak despite marginally significant correlations with some of the Pacific SST indices in austral summer and preceding spring. We note that the significant positive correlation between the DMI and AUSM index in JF and the following seasons does not mean a positive IOD development. Rather, this positive correlation simply means that local cool SST anomalies over the SEIO spread into the eastern pole of IOD (Fig. 2c), resulting in an apparent projection onto DMI.

The interannual variances of bimonthly-mean rainfall anomalies over NAUS are shown in Fig. 1a (solid blue line). The variance has a distinct peak in $\mathrm{JF}$, the climatological AUSM season. In order to verify the weak influence of SST variability on the rainfall variance, we have removed the SST-forced component from the bimonthly-mean NAUS rainfall anomalies following a statistical method used in 
Sekizawa et al. (2018). In this method, we first derive five leading empirical orthogonal functions (EOFs) and principal components (PCs) of tropical $\left(20^{\circ} \mathrm{S}-20^{\circ} \mathrm{N}\right)$ SST anomalies averaged over three months including the two target months for the rainfall anomaly and the preceding month (Fig. S2). For example, when applying to JF-mean rainfall, the corresponding EOFs and PCs are obtained based on DJF-mean SST. We then remove the regression anomalies of NAUS rainfall onto the five SST PCs to obtain the internal component of the rainfall variability as a residual. Sekizawa et al. (2018) confirmed that the magnitude and spatial distribution of internal variability in JF-mean convective activity extracted by this statistical method is consistent with those reproduced by the atmospheric general circulation model simulation with daily climatological-mean SST fields. As in the total variance, the internal variance also peaks in JF (Fig. 1a, dashed red line). The fraction of internal variance is large in austral summer (exceeding 80\%), while it is relatively small in spring and autumn except in April-May (Fig. 1b), consistent with the fact that the influence from tropical SST variability seasonally weakens through the monsoon season (Hendon et al. 2012; Sekizawa et al. 2018).

\section{b. Persistence of anomalous rainfall}

If an internal variability is dominant in the interannual variability of JF-mean NAUS rainfall, one may wonder to what extent the internal variability can provide persistence for the anomalous rainfall. To see this, we examine the onemonth lag autocorrelation of the NAUS rainfall anomaly averaged over the nine stations. As indicated in Fig. 1c with the blue line, monthly rainfall anomalies are overall positively correlated with those in the following month. Despite the weaker influence of SST variability in JF (Fig. 1b), rainfall anomalies over NAUS in JF are comparably persistent to that in October-November and MarchApril. However, the correlation is weak between December and January, when NAUS usually undergoes the monsoon onset. It is also weak between February and March when the monsoon usually retreats. These weak correlations suggest that processes involved in the rainfall anomaly may differ among the pre-monsoon, monsoon and postmonsoon seasons.

The red line in Fig. 1c shows the one-month lag correlation for the internal component of rainfall anomalies obtained in a similar manner to that applied to the rainfall variance (Fig. 1a). In austral spring and autumn, the correlation for the internal component is weaker than that for the total rainfall variability, consistent with relatively stronger influence from the SST variability (Fig. 1b). In JF, however, the correlation of the internal anomalies is almost unchanged from that of the total, and still statistically significant. These results suggest that the internal variability in the AUSM system can provide a certain level of persistence to the NAUS rainfall anomalies without strong influence from SST variability.

\section{Mechanisms for the persistent moisture supply}

\section{a. Moisture transport and oceanic evaporation}

Precipitation and 10-m wind anomalies regressed onto the AUSM index (Fig. 3a) feature local intensification of the AUSM system. The positive precipitation anomaly is confined to NAUS, as also shown in Fig. 2a. The anomalous cyclonic circulation forms as a Rossby-wave response to the enhanced NAUS convection (Matsuno 1966; Gill 1980), which is well reproduced in the LBM experiment forced by local diabatic heating over NAUS (Fig. 4). In contrast, over the subtropical southern Indian Ocean $\left(\sim 90^{\circ} \mathrm{E}\right)$, convective activity is suppressed in association with the anomalous equatorward winds.

To investigate maintenance mechanisms for the distinct AUSM variability, we first examine the anomalous surface latent heat flux (LHF) over the SEIO and moisture transport into NAUS. Associated with the enhanced AUSM activity, anomalous column-integrated water vapor (CWV) flux converges into NAUS from the tropical SEIO (Fig. $3 b)$. The anomalous water vapor flux is cyclonic, following the anomalous surface winds (Fig. 3a). These anomalies suggest that the intensified lowlevel westerlies bring a greater amount of moisture into the enhanced convection over NAUS from the climatologically warm tropical Indian Ocean.

In association with the intensified moisture transport from the Indian Ocean into NAUS, enhanced evaporation is evident over the tropical SEIO just upstream of the intensified convection over NAUS (Fig. 3b). Through a linearized bulk formula for anomalous LHF, Sekizawa et al. (2018) showed that the enhanced evaporation is primarily induced by the intensified surface wind speed. The associated surface cooling (Fig. 2c) acts to suppress evaporation, but this is well overcome by the contribution from the strengthened surface winds. We have confirmed that the same analysis as in Sekizawa et al. (2018) for the LHF anomalies 
JF regression anomalies

(a) Precipitation \& $10 \mathrm{~m}$ wind

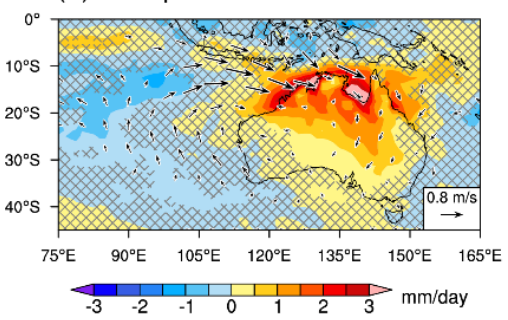

(c) MSE

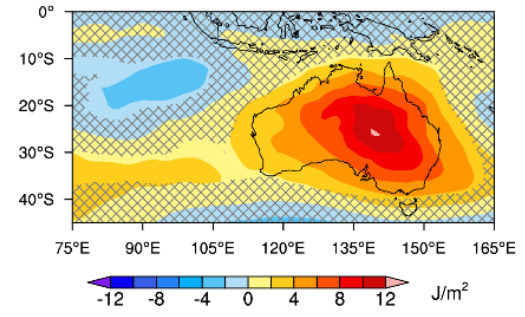

(b) Evaporation \& CWV flux

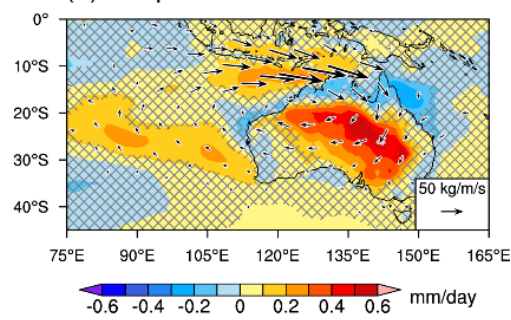

(d) Column-integrated water vapor

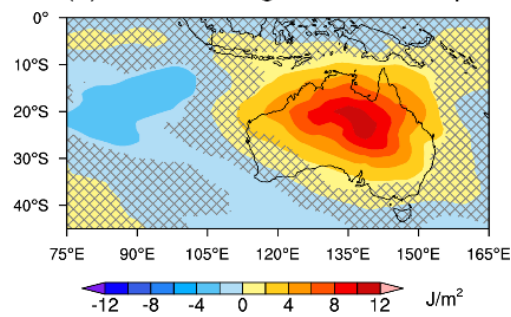

Fig. 3. JF-mean anomalies of (a) precipitation, (b) evaporation, (c) column-integrated MSE and (d) the contribution of CWV to MSE, all regressed onto the AUSM index (shading), based on JRA-55 (1958-2021). Areas with significance below the 95\% confidence level are hatched. Vectors in (a) and (b) indicate 10-m wind and CWV flux anomalies, respectively, whose scaling is given at the lower-right corner of each panel. Vectors are plotted only where either the zonal or meridional component is significant at the $95 \%$ confidence level.

regressed onto the AUSM index in the present study leads to similar results (see Fig. S3).

\section{b. JF-mean MSE budget}

The column-integrated MSE budget analysis for the JF-mean anomalies elucidates the importance of the anomalous evaporation over the tropical SEIO for the persistent anomalous convection over NAUS. Associated with the strong AUSM, JF-mean MSE significantly increases over the Australian Continent (Fig. 3c). The MSE anomaly is mostly explained by the increased CWV north of $30^{\circ} \mathrm{S}$ (Fig. 3d), consistent with the assumption of weak temperature gradients in the tropics. We can, therefore, interpret the MSE anomaly budget in terms of the moisture budget. Consistent with the observational fact that tropical precipitation is sensitive to the local CWV (Bretherton et al. 2004; Holloway and Neelin 2009), precipitation significantly increases over the region with increased CWV (Figs. 3a and 3d). As depicted in Fig. 5a, the JF-mean tendency of MSE anomalies is almost zero everywhere, implying that the budget is almost balanced as the JF-mean. To see how this balance is achieved, we first look at the MSE flux convergence and forcing anomalies. As shown in Fig. 5c, the anomalous MSE forcing is concentrated in the tropical SEIO, where the intensified monsoonal westerlies and resultant enhanced evaporation are evident (Figs. 3a and 3b). This MSE forcing anomaly is balanced with the anomalous MSE flux divergence (Fig. 5b). By contrast, both

\section{LBM experiment}

(a) $925 \mathrm{hPa}$ wind response to NAUS heating

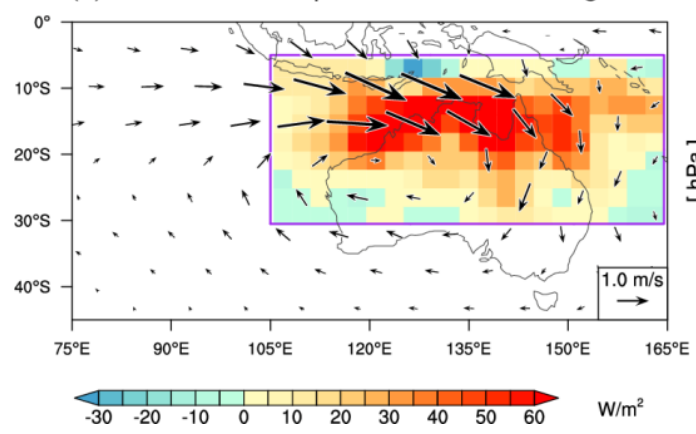

(b) Heating profile

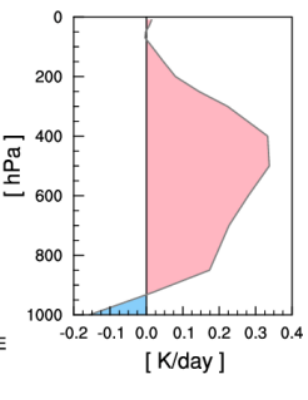

Fig. 4. (a) Steady response of $925-\mathrm{hPa}$ wind (vectors) in the LBM experiment forced by regression anomalies onto the AUSM index of JF-mean diabatic heating, whose column-integrated values are denoted with shading. (b) Vertical profile of the prescribed diabatic heating averaged over the purple box in (a). 


\section{MSE budget for JF anomalies}

(a) MSE tendency

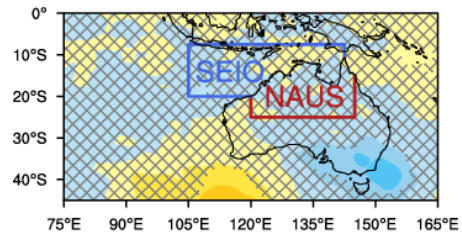

(b) MSE flux convergence

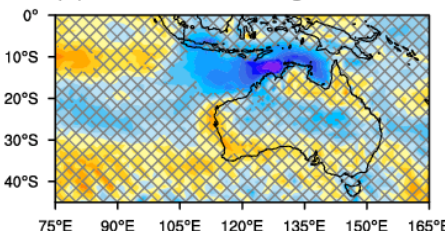

(c) MSE Forcing

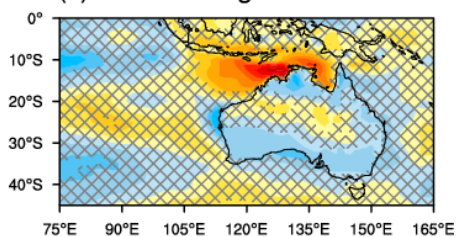

$\mathrm{W} / \mathrm{m}^{2}$
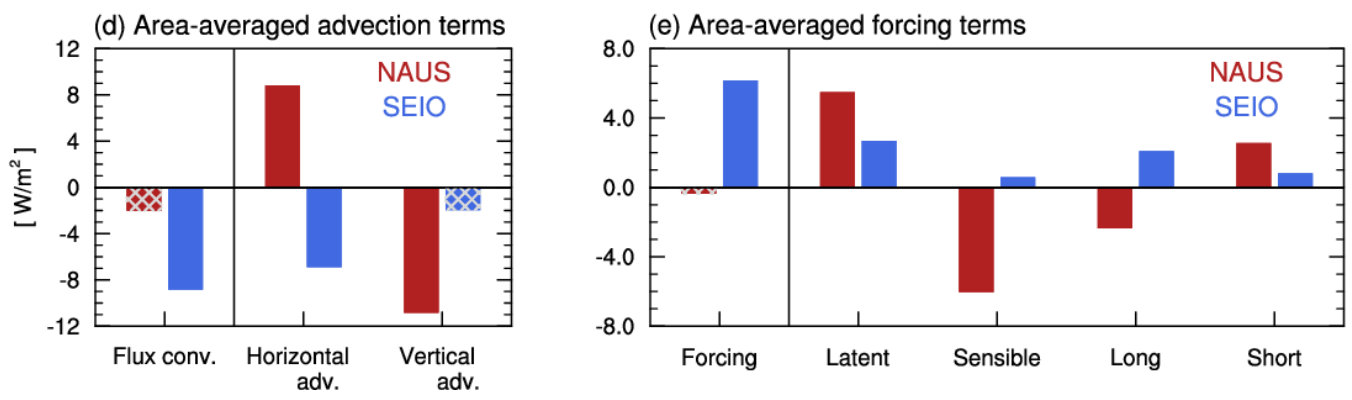

Fig. 5. (a-c) JF-mean anomalies of column-integrated (a) MSE tendency, (b) MSE flux convergence and (c) MSE forcing regressed onto the AUSM index. (d-e) JF-mean anomalies of column-integrated (d, from left to right) net MSE flux convergence, horizontal advection and vertical advection, and (e, from left to right) net MSE forcing, surface LHF, surface sensible heat flux, longwave radiation and shortwave radiation, averaged separately over NAUS (brown bars) and the tropical SEIO (blue bars), regressed onto the AUSM index, based on JRA-55 (1958-2021). Domains for the spatial averaging are indicated in (a). Hatched areas and bars denote the significance below the $95 \%$ confidence level.

anomalous MSE flux divergence and forcing are much weaker over NAUS.

Figures $5 \mathrm{~d}$ and $5 \mathrm{e}$ show decompositions of the anomalous MSE flux divergence and forcing terms, respectively, spatially averaged over the oceanic domain in SEIO and the continental domain in NAUS (denoted in Fig. 5a). The forcing anomaly in SEIO is primarily due to the anomalous LHF and additionally the anomalous longwave heating (Fig. $5 \mathrm{e}$, blue bars). The latter may be caused by reduced outgoing longwave radiation due to the enhanced deep convection. The offsetting MSE tendency through the anomalous flux divergence in this domain is mostly accounted for by the horizontal advection (Fig. 5d, blue bars). This indicates that a major fraction of the anomalous MSE supply is not consumed by local enhancement of convective activity but balanced by the exportation through the anomalous horizontal advection out of the domain.

Over the continental domain in NAUS, the netzero anomalous MSE forcing is achieved through the counteracting contributions between enhanced LHF and suppressed sensible heat flux from the wetter and cooler land surface (Fig. 5e, red bars). At the same time, the positive contribution from the horizontal MSE advection is balanced by the negative contribution from the vertical advection (Fig. 5d, red bars). This indicates that the increased MSE through the anomalous horizontal advection is almost totally consumed by the anomalous vertical advection associated with the enhanced convection. As depicted in Fig. 5a, the land domain is located immediately downstream of the oceanic domain under the monsoon westerlies. Therefore, the MSE budget analysis reveals that the anomalous MSE supply to NAUS due to the enhanced evaporation in the SEIO and the intensified monsoon westerlies is expended by the enhanced convective activity. Together with the intensified AUSM circulation by enhanced convective heating (section 4a), our analysis strongly supports the hypothesis that the wind-evaporation-convection feedback sustains the anomalous convection over NAUS (Sekizawa et al. 2018).

Table 1 compares GMS over NAUS (the continental domain in Fig. 5a) between the climatology and a typical strong AUSM year. In deriving the climatological GMS, we first calculated the climatologies of area-averaged convergence of the CWV and MSE fluxes separately before taking their ratio. Likewise, we calculated GMS for the typical strong AUSM year by taking their ratio after the regressed anomalies of the CWV and MSE flux convergence had been added to their climatological values. Climatologically, the horizontal GMS is positive, indicating that relatively dry air imported from outside of the domain acts to weaken the convection. When AUSM is stronger than the 
Table 1. Precipitation $(P)$, MSE forcing $(Q)$ and GMS $\left(\Gamma=\Gamma_{h}+\Gamma_{v}\right)$ over NAUS in climatology and a typical strong AUSM year based on the regressed anomalies onto the AUSM index (see the text for the details), and corresponding fractional change of precipitation assessed by Eq. (5).

\begin{tabular}{c||c|c|c|c|c} 
& $\begin{array}{c}P \\
{\left[\mathrm{~mm} \mathrm{day}^{-1}\right]}\end{array}$ & $\begin{array}{c}Q \\
{\left[\mathrm{~W} \mathrm{~m}^{-2}\right]}\end{array}$ & $\Gamma$ & $\Gamma_{h}$ & $\Gamma_{v}$ \\
\hline \hline Climatology & 5.19 & 46.5 & 1.55 & 1.86 & -0.31 \\
\hline Strong AUSM & 6.43 & 46.1 & 0.99 & 1.03 & -0.05 \\
\hline \hline $\begin{array}{c}\text { Fractional change } \\
\text { of } P\end{array}$ & $+23.9 \%$ & $-0.8 \%$ & $+36.3 \%$ & $+53.2 \%$ & $-16.9 \%$
\end{tabular}

climatology, the GMS decreases due to a reduction in its horizontal component. This implies that the anomalously wet inflow from SEIO into NAUS reduces its effect of weakening the convective activity. Meanwhile, the climatological vertical GMS is weakly negative, indicating that convection acts to increase MSE through a slightly unstable vertical profile of MSE. The vertical component becomes closer to zero when the AUSM is strong, implying the relatively stable MSE profile. In terms of GMS [Eqs. (2) and (3)], the fractional change in precipitation can be expressed as

$$
\frac{P^{\prime}}{\bar{P}}=\frac{Q^{\prime}}{\bar{Q}}-\frac{\Gamma_{h}^{\prime}}{\bar{\Gamma}}-\frac{\Gamma_{v}^{\prime}}{\bar{\Gamma}}
$$

where an overbar and prime denote JF-mean climatology and an anomaly, respectively. We evaluate the contributions from individual terms in Eq. (5) to the precipitation change over NAUS under the strong AUSM (Table 1). Consistent with the GMS change, anomalous precipitation over NAUS is largely accounted for by the reduction in the horizontal GMS. This result reveals that the increased moisture transport from the Indian Ocean is more important to the enhanced NAUS rainfall, rather than local changes in the surface flux or stability.

\section{c. Soil moisture and land-surface evaporation}

In the previous subsections, we have discussed the anomalous moisture supply from the tropical SEIO associated with the enhanced oceanic evaporation. However, Fig. $3 \mathrm{~b}$ also shows marked positive evaporation anomalies over the Australian Continent greater than those over the SEIO. In this subsection, we thus investigate the role of landsurface evaporation and soil moisture anomalies on the NAUS rainfall variability.

We first examine time evolutions of the 15-day running-mean anomalous CWV budget over NAUS (the continental domain in Fig. 5a). The balance between the CWV flux convergence and precipitation anomalies is obvious throughout JF
(Fig. 6a, blue and green lines), and therefore the net CWV tendency is much smaller than those offsetting contributions from these two terms (Fig. 6a, black line). In addition, anomalous evaporation makes a secondary positive contribution (Fig. 6a, red line) from mid-January to mid-February with the amplitude of $\sim 20 \%$ of the anomalous CWV flux convergence, and its fractional contribution becomes even larger near the end of the AUSM season as the moisture inflow rapidly decreases. Since the land-surface moistening lags the precipitation anomaly (Fig. 6a, shading), the evaporation tends to increase from mid-January two or three weeks after the AUSM onset. Indeed, spatial patterns of evaporation and soil moisture anomalies at the beginning of February well correspond each other except in the Top End and Cape York Peninsula (Figs. 7b and 7d). By contrast, there are no organized significant anomalies of the variables at the beginning of January (Figs. 7a and 7c).

To further investigate the role of soil moisture in maintaining AUSM rainfall anomalies, we have counted the number of years with above-median rainfall averaged in early (1st-10th), middle (11th20th) and late (21st-29th) February, separately for cases with wet and dry soil conditions on February 1st. The wet (dry) soil case has been defined by years when soil moisture averaged over NAUS on February 1st was more (less) than the upper (lower) tertile. Note that the AUSM index is not taken into account in this analysis. In the wet soil case, rainfall in early and mid-February tends to be above median more frequently than in the dry case, whereas there is no preference in late February (Fig. 6b). Interestingly, the difference between the wet and dry cases is greater in mid-February than in early February. When we count the number of years with below-median rainfall in the same manner, essentially the opposite result is obtained (Fig. 6c). These results suggest that the amount of NAUS soil moisture at the beginning of February subsequently affects the anomalous rainfall up to mid-February. Considering that soil moisture is largely determined 
(a) Anomalies of CWV budget and soil moisture over NAUS

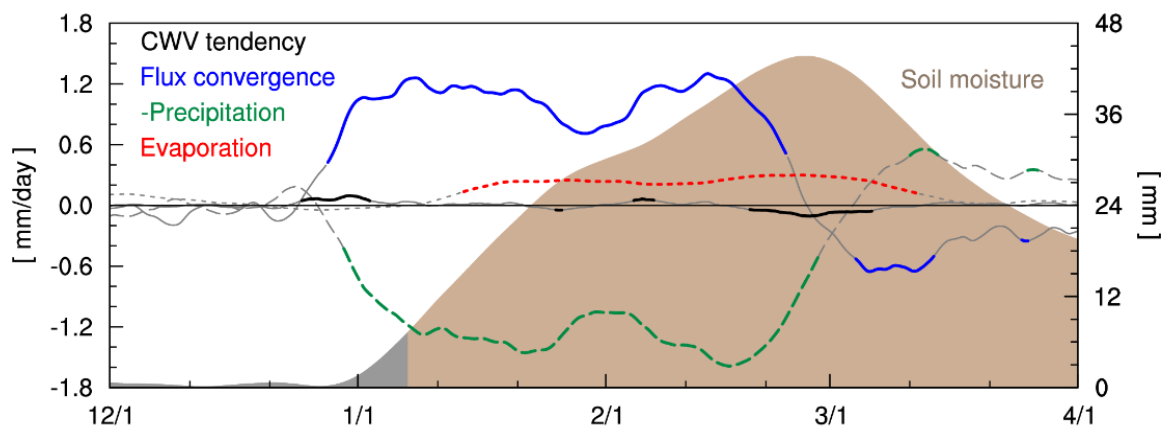

(b) Above median rainfall

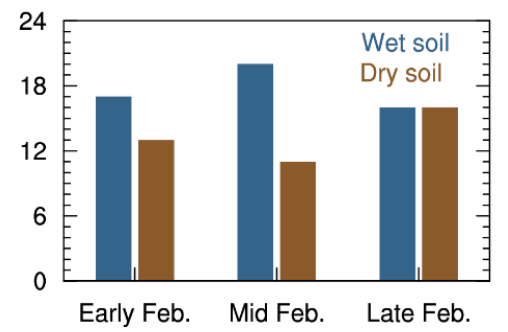

(c) Below median rainfall

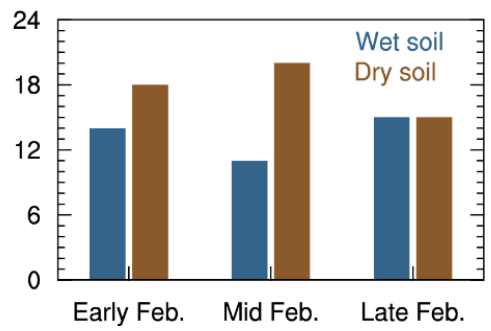

Fig. 6. (a) Regression anomalies (left axis, $\mathrm{mm} \mathrm{day}^{-1}$ ) onto the AUSM index of 15-day running-mean (black line) CWV tendency, (blue) CWV flux convergence, (green) sign-reversed precipitation and (red) evaporation, averaged over the NAUS domain indicated in Fig. 5a, based on JRA-55 (1958-2021). Brown shading denotes corresponding anomalies of soil moisture (right axis), based on AWRA-L (1958-2019). Gray lines and shading indicate the significance below the 95\% confidence level. (b) Number of years with above-median mean NAUS rainfall in early (1st-10th), middle (11th20th) and late (21st-29th) February, counted separately for wet (blue bars) and dry (brown bars) NAUS soil moisture cases at the beginning of February. (c) Same as in (b), but for the below-median rainfall.

\section{Regression anomalies onto AUSM index}

(a) Evapotranspiration on Jan 1st

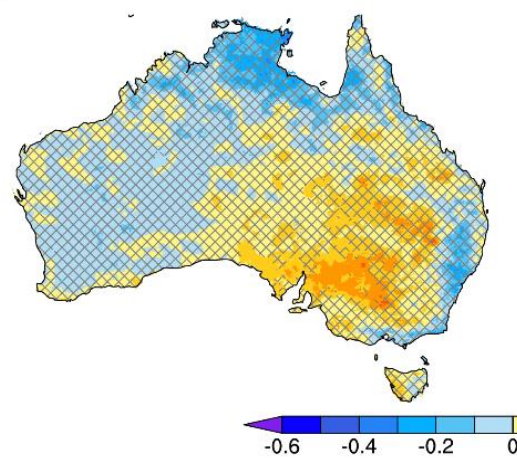

(c) Soil moisture on Jan 1st

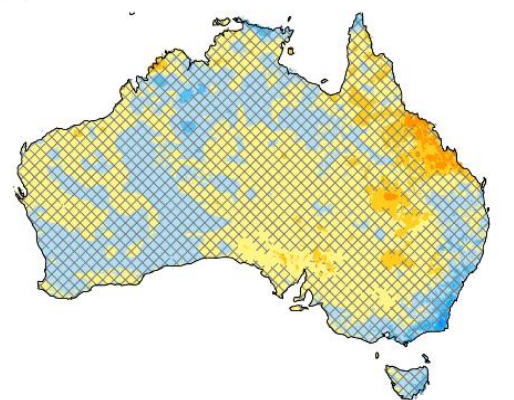

(b) Evapotranspiration on Feb 1st

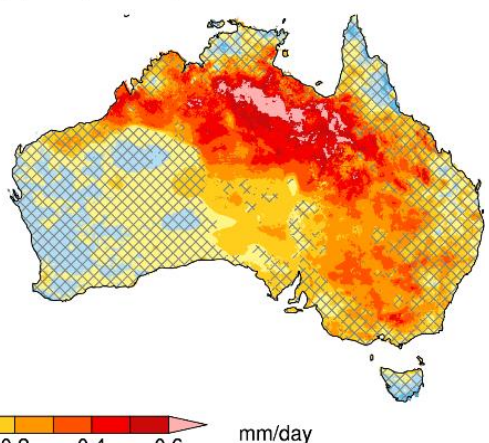

(d) Soil moisture on Feb 1st

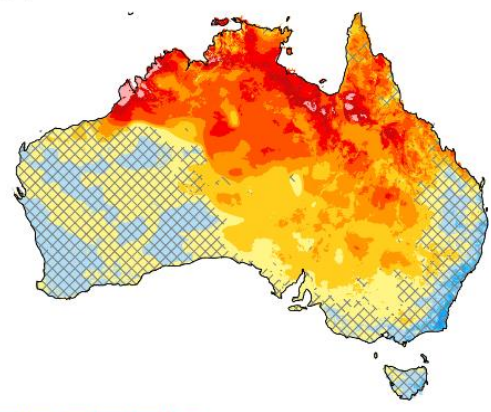

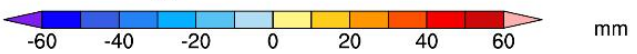

Fig. 7. Regression anomalies onto the AUSM index of $(a, b)$ evapotranspiration and $(c, d)$ soil moisture anomalies on (a, c) January 1st and (b, d) February 1st, based on AWRA-L (1958-2019). Areas with the significance below the 95\% confidence level are hatched. 
by accumulated rainfall in January, the positive feedback between rainfall and soil moisture promotes the persistency of NAUS rainfall anomalies through anomalous land-surface evaporation. As shown in Figs. 3a and 3d, rainfall and CWV anomalies are not confined to NAUS, but extend to the central and eastern inland regions. The anomalies of soil moisture and land-surface evaporation are also significant in these regions (Figs. $7 \mathrm{~b}$ and $7 \mathrm{~d}$ ), which can maintain the rainfall anomalies along with the contribution from anomalous southward CWV flux from NAUS (Fig.3b).

\section{Role of air-sea interaction}

As shown in Sekizawa et al. (2018), influence of the AUSM variability extends into subsurface layers of the tropical SEIO. In the spring (pre-monsoon season) climatology under the prevailing trade
Indonesian coast through offshore Ekman transport (Fig. 8a). After the climatological AUSM onset, in contrast, the monsoonal westerlies prevail over this region, deepening both the oceanic mixed layer and thermocline associated with onshore Ekman transport (Fig. 8b). As depicted in Fig. 8c, the anomalously strong AUSM emphasizes these climatological features. The stronger surface westerlies act to cool and thicken the ocean mixed layer through augmented evaporation and mixing, but at the same time they lead to thermocline deepening through intensified Ekman downwelling. The thermocline deepening is manifested as warm anomalies below the mixed layer. Sekizawa et al. (2018) argued that these subsurface anomalies can suppress the SST cooling and resultant negative feedback onto the anomalous evaporation. (a) ON (climatology)

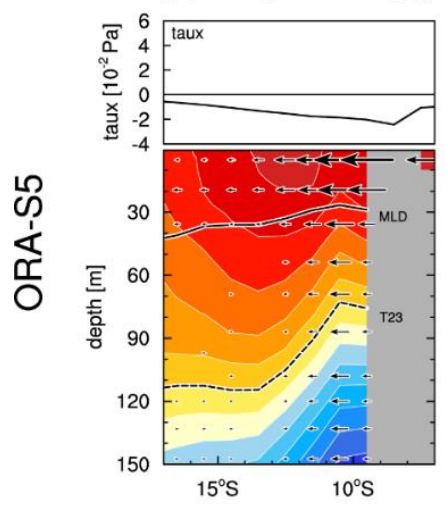

(d) ON (climatology)

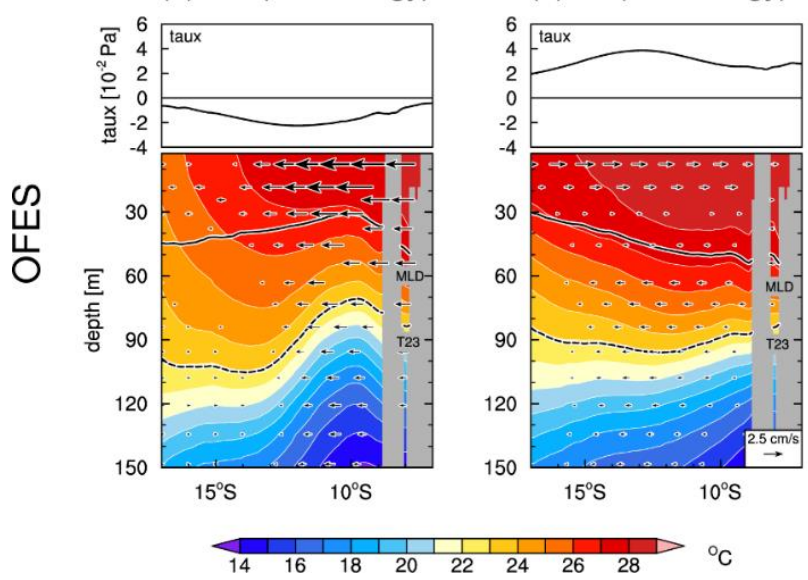

(b) JF (climatology)

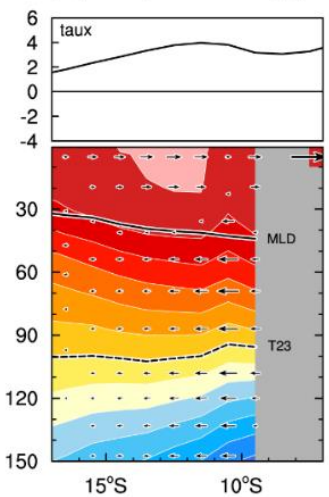

(e) JF (climatology)

(f) JF (anomaly)

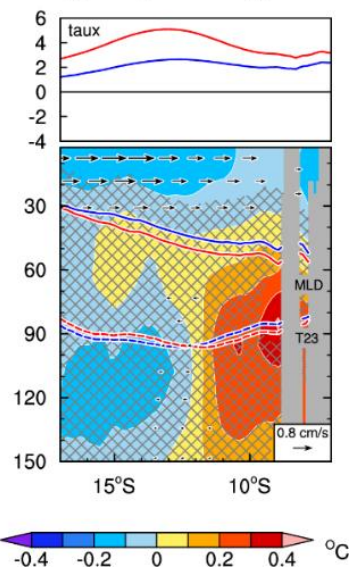

Fig. 8. Meridional sections of longitudinal-mean $\left(105^{\circ}-125^{\circ} \mathrm{E}\right)$ temperature (shading) and meridional velocity (vectors) for (a, d) ON-climatology, (b, e) JF-climatology and (c, f) JF-mean anomalies regressed onto the AUSM index, based on (a-c) ORA-S5 and (d-f) OFES hindcast experiment (1980-2014). Scaling for the vectors is given at the lower-right corner of (e) and (f) for the climatologies and anomalies, respectively. Hatched domains denote the significance of temperature anomalies below the $90 \%$ confidence level, and vectors are plotted only where the anomalies are significant at the $90 \%$ confidence level. Black lines in $(\mathrm{a}, \mathrm{b}, \mathrm{d}, \mathrm{e})$ indicate the corresponding climatologies of zonal wind stress (upper, solid), mixed layer depth (lower, solid) and $23^{\circ} \mathrm{C}$ isotherms (dashed). Red and blue lines in (c, f) represent their JF-mean anomalies added onto and subtracted from the climatology, respectively.

easterlies, the thermocline shoals along the 
Mixed-layer heat budget for JF anomalies
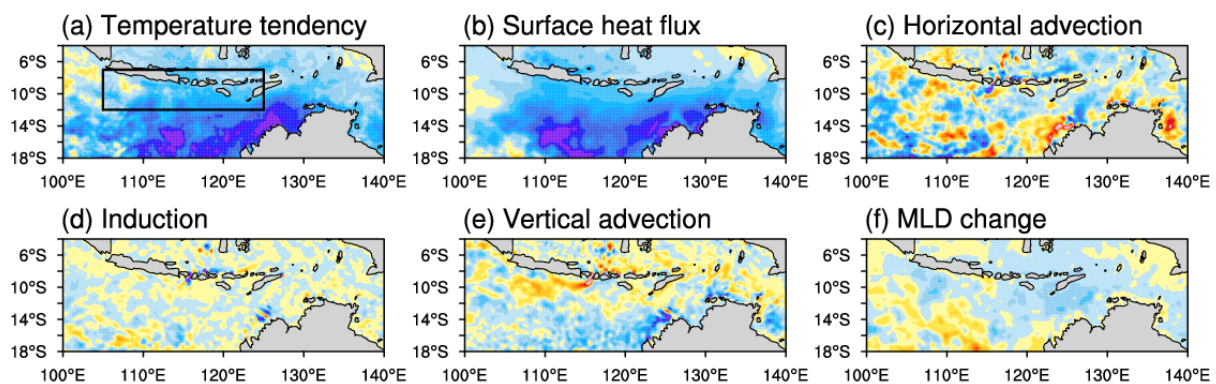

(e) Vertical advection
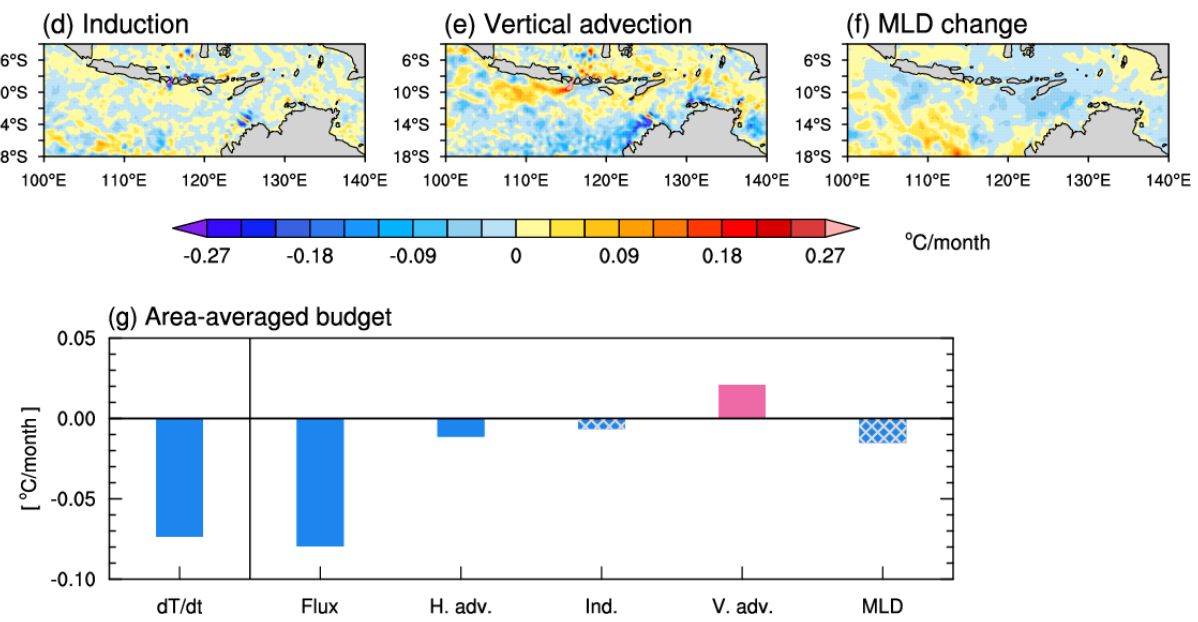

Fig. 9. JF-mean anomalies onto the AUSM index of (a) mixed-layer temperature tendency, and contributions from (b) surface heat flux, (c) horizontal advection in the mixed-layer, (d) induction, (e) vertical advection and (f) temporal evolution of the mixed-layer depth, based on the mixed layer heat budget analysis in Eq. (4) applied to the OFES hindcast experiment. (g) JF-mean anomalies of these terms averaged over the domain indicated with a black box in (a). Hatched bars denote the significance below the $90 \%$ confidence level.

To quantify this damping effect, we have performed a mixed-layer heat budget analysis based on the OFES hindcast experiment. We first examine how realistically the hindcast experiment reproduces the seasonal evolution and AUSM response of temperature profile as in the ocean reanalysis (ORAS5). When we compare Figs. 8d-f with Figs. 8a-c, one noticeable difference is that the axis of surface wind stress is displaced poleward in OFES, presumably owing to the coarse resolution of the wind field prescribed to the model. Correspondingly, mixed-layer responses to the anomalous AUSM are shifted poleward slightly (Figs. 8c and 8f). In addition, the climatological mixed layer in OFES tends to be cooler by $\sim 1^{\circ} \mathrm{C}$ and thicker by $\sim 5-10 \mathrm{~m}$ than in the reanalysis (Figs. 8b and 8e). Nevertheless, OFES can acceptably reproduce overall temperature distributions for both the climatology and anomalies.

Figure 9 exhibits the mixed-layer heat budget for the tropical SEIO based on JF-mean anomalies in the OFES hindcast experiment regressed onto the AUSM index. Associated with the strong AUSM, downward surface heat flux is significantly reduced due to the enhanced evaporation and less insolation, thus acting to cool the mixed layer (Fig. 9b). In fact, the net mixed-layer temperature tendency is mostly attributable to this anomalous surface flux (Fig. 9a). Meanwhile, the anomalous vertical advection acts to warm the mixed-layer moderately north of $12^{\circ} \mathrm{S}$ (Fig. 9e). Since the dynamical terms tend to have smallscale features (Fig. 9c-f), we assess the budget based on the spatial averages within the domain $\left[12-7^{\circ} \mathrm{S}\right.$, $105-125^{\circ} \mathrm{E}$ ] (black box in Fig. 9a). The anomalous warming due to the vertical advection term cancels out $30 \%$ of the dominant anomalous cooling by the surface heat flux reduction (Fig. 9g). The anomalous mixed-layer deepening also contributes to the mixed-layer cooling, but it is small and statistically insignificant.

The vertical advection term is a product of vertical motion and stratification, and thus its anomaly can be decomposed into the two components as

$$
\left[\left(w \frac{\partial T}{\partial z}\right)^{\prime}\right] \approx\left[w^{\prime} \frac{\partial \bar{T}}{\partial z}\right]+\left[\bar{w} \frac{\partial T^{\prime}}{\partial z}\right] .
$$

As shown in Figs. 10a and 10b, the anomalous mixed-layer warming that the anomalous vertical advection acts to induce is primarily accounted for by the anomalous vertical motion acting on the mean stratification, whereas the other term makes almost no contribution. This implies that the subsurface warm anomalies under the strong AUSM (Figs. 8c and $8 \mathrm{f}$ ) do not directly contribute to the anomalous mixed-layer warming. Rather, what is essentially important is the anomalous downward motion induced by the anomalous surface wind stress. Figures $10 \mathrm{c}$ and $10 \mathrm{~d}$ illustrate anomalous vertical 


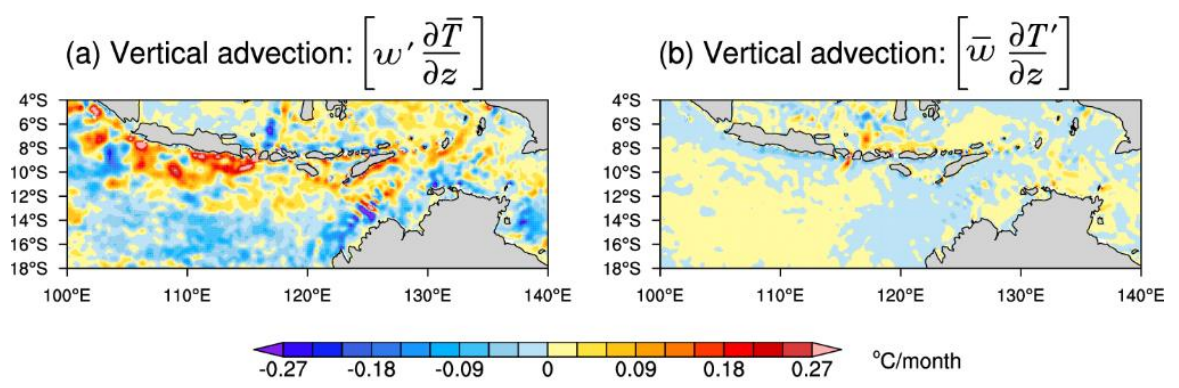

(c) Vertical velocity at $45.6 \mathrm{~m}$

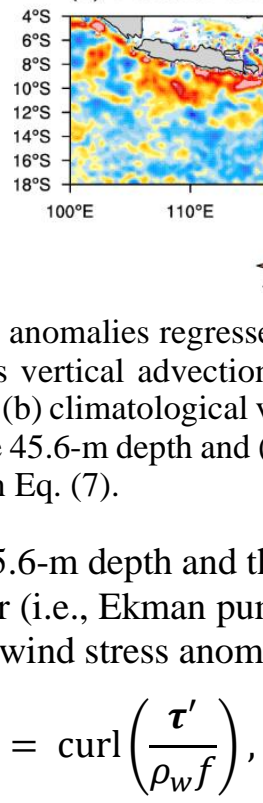

where $\boldsymbol{\tau}^{\prime}$ and $f$ are anomalous wind stress vector and Coriolis parameter, respectively. The anomalous anticyclonic (counterclockwise) shear of the wind stress along the equatorward flank of the monsoonal westerlies induces anomalous downward motion along the coast of Indonesia by enhancing the Ekman downwelling (north of $\sim 12^{\circ} \mathrm{S}$, Fig. 10d). Indeed, anomalous vertical velocity at the 45.6-m depth tends to be downward as shown in Fig. 10c. Note that there may be an additional contribution from the reduced coastal upwelling just off the Indonesian coast, which cannot be represented in Eq. (7). Therefore, we can conclude that intensified monsoon westerlies in a strong AUSM year and their anticyclonic shear force anomalous downward motion in the subsurface layer, partially offsetting the anomalous cooling effect of surface heat flux, despite the anomalous deepening of the mixed layer.

\section{Summary and discussion}

The influence of tropical SST variability on NAUS rainfall is known to be weaker in austral summer than in spring. Based on observational data, we have confirmed that internal variability dominates in the interannual variability of mean NAUS rainfall in the AUSM season, whereas the motion at the 45.6-m depth and that at the bottom of
the Ekman layer (i.e., Ekman pumping velocity) $w_{E}^{\prime}$ estimated from wind stress anomalies as

$$
w_{E}^{\prime}=\operatorname{curl}\left(\frac{\boldsymbol{\tau}^{\prime}}{\rho_{w} f}\right),
$$

(d) Ekman pumping velocity: $w_{E}$

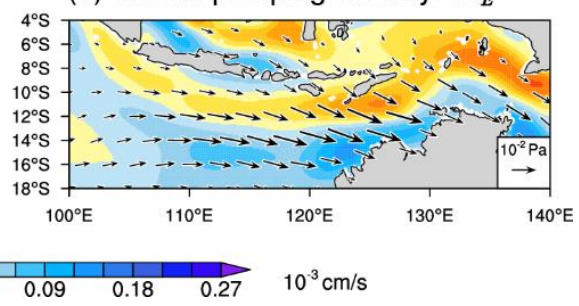

Fig. 10. JF-mean anomalies regressed onto the AUSM index (shading) of the mixed-layer temperature tendencies due separately through (a) anomalous vertical velocity acting on the climatological l vertical velocity acting on the anomalous temperature gradient [Eq. (6)], and vertical existence of certain maintenance mechanisms inherent to the AUSM system. In this study, we have investigated the maintenance mechanisms of the AUSM variability and demonstrated its selfsustaining nature under the atmosphere-ocean-land surface interaction, which is illustrated schematically in Fig. 11.

Associated with the stronger AUSM than its climatology, the low-level cyclonic circulation intensifies as a Rossby-wave response to the anomalous diabatic heating over NAUS. The strengthening of the surface monsoon westerlies enhances oceanic evaporation over the tropical SEIO and downstream moisture transport into NAUS. This wind-evaporation feedback, originally pointed out by Sekizawa et al. (2018), is further substantiated through the MSE budget analysis based on reanalysis data. In NAUS with enhanced convective activity, the anomalous vertical advection expends MSE anomalies supplied through the anomalous horizontal advection. This result and associated GMS diagnosis have elucidated that the enhanced convection over NAUS is sustained through the wetter-than-usual low-level inflow from the tropical SEIO rather than local surface heat flux anomalies or a decrease in vertical stability. Meanwhile, in the tropical SEIO, increased MSE exportation due to the horizontal advection is 
replenished by the locally enhanced MSE forcing, which is accounted for primarily by wind-induced LHF anomalies with an additional contribution of anomalous longwave radiation.

These results support the notion that the strengthening of the monsoonal circulation and resultant evaporation increase are essential for sustaining the anomalous AUSM activity. This feedback mechanism can be considered as a manifestation of the wind-induced surface heat exchange (WISHE; Emanuel 1987; Emanuel et al. 1994), in which the increase in surface heat flux induced by an intensified low-level circulation warms the entire troposphere through the moist convection, feeding back to the atmospheric circulation. The mechanism may also be similar to conditional instability of the second kind (CISK; Ooyama 1982; Craig and Gray 1996) in a broad sense, if focusing on an aspect of positive feedback between latent heat release associated with convections and large-scale low-level convergence. In addition, the anomalous MSE forcing due to longwave radiation suggests a potential role of positive cloud-radiation feedback, which may be similar to that discussed in some studies on MJO (e.g., Zhang et al. 2019). While the mechanism we have proposed focuses on the AUSM variability that reflects its regional characteristics, a similar mechanism can work in other monsoon systems if it is extended to a more general concept that connects the large-scale circulation, wind-induced oceanic evaporation and continental convection.

For this feedback mechanism to work effectively, the negative SST anomalies in the tropical SEIO due to the stronger AUSM must be weak enough to prevent evaporation from being reduced. We have investigated ocean current and temperature anomalies in the SEIO and found that the anomalous monsoon westerlies modulate the subsurface vertical motion and associated vertical temperature advection, thereby acting to damp the SST anomalies. This damping effect induced by ocean dynamics is quantitatively verified through the mixed-layer heat budget analysis. We also note that the seasonal deepening of the mixed layer after the monsoon onset acts to suppress the development of SST anomalies compared to other seasons. In this sense, we consider the AUSM variability to be internal to the coupled AUSM system rather than a pure atmospheric internal variability.

We have also found a significant increase in land-surface evaporation in February associated with the development of soil moisture anomalies in the strong AUSM year, reaching $20 \%$ of the anomalous moisture flux convergence. Our analysis has also shown that, when the soil is wetter (dryer) than climatology at the begging of February, rainfall tends to increase (decrease) until mid-February. This tendency suggests the role of soil moisture as a memory for the persistent anomalous rainfall. The role of the atmosphere-land surface interaction, as well as the role of the wind-evaporation feedback and ocean dynamics, would be further elucidated in future studies through detailed analyses of observations, intercomparison of numerical models and sensitivity experiments.

The relationship between AUSM rainfall and ENSO is known to exhibit a clear long-term modulation coherent with the Interdecadal Pacific Oscillation (IPO): stronger correlation in its negative phase and weaker correlation in its positive phase (Power et al. 1999; Cai et al. 2010; Heidemann et al. 2022). Therefore, the internal variability we have investigated in this study may also be affected by the IPO phase, and the influence may be interpreted from the viewpoint of the maintenance mechanisms

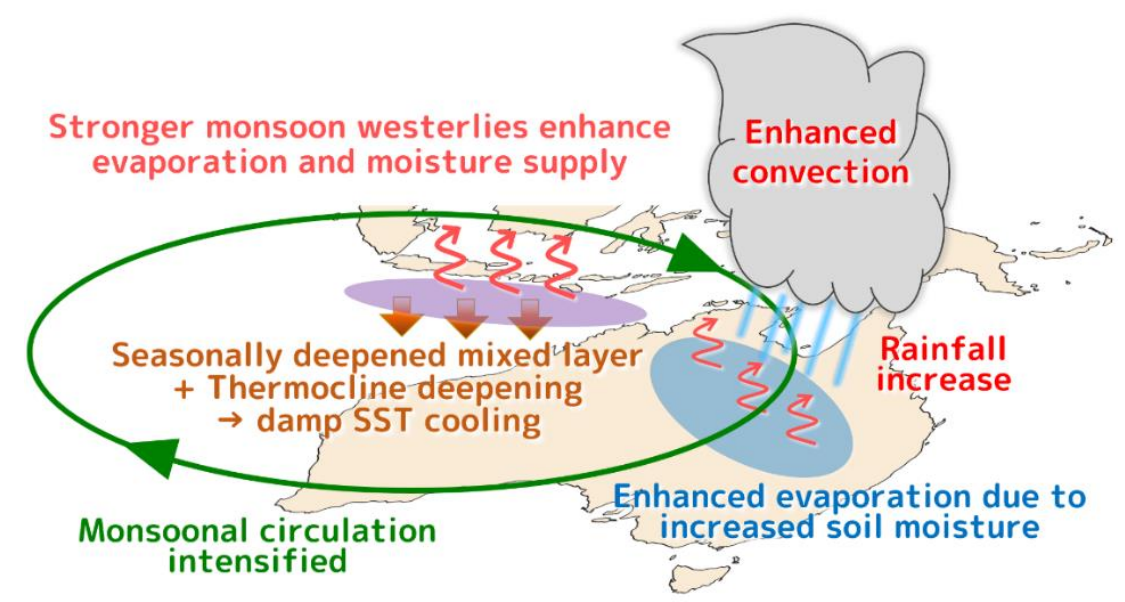

Fig. 11. Schematic of the self-sustaining mechanisms of the AUSM variability, including wind-evaporation-convection feedback, dynamical air-sea interaction and soil moisture memory. This figure features the phase of the stronger AUSM. See the text for details. 
we have proposed. Future studies may also apply them to interpreting reproducibility and future change of the AUSM variability in climate model simulations.

In this study, we have discussed the maintenance mechanisms of AUSM variability, but its trigger remains to be clarified. As shown in sections 3 and 4 , there appears no precursory signal in SST or soil moisture before the onset of the AUSM. This implies that it is difficult to predict the AUSM rainfall with monthly to seasonal leads. Nevertheless, once we identify any signal that could trigger the AUSM variability a few weeks before the onset, it will provide useful predictability on intraseasonal timescales. Especially, it would be worthwhile to investigate the process by which CWV accumulates over the Australian Continent within a relatively short period around the AUSM onset.

\section{Acknowledgments}

This work is supported in part by the Japanese Ministry of Education, Culture, Sports, Science and Technology through the Arctic Challenge for Sustainability (ArCS) II Program (JPMXD1420318865), by Japan Society for the Promotion of Science through Grants-in-Aid for Scientific Research JP18H01278, JP19H05702, JP19H05703, and JP20H01970, by the Japan Science and Technology Agency through COINEXT (JPMJPF2013), and by the Environmental Restoration and Conservation Agency of Japan through the Environmental Research and Technology Development Fund (JPMEERF20192004). We also acknowledge the assistance of resources from the National Computational Infrastructure supported by the Australian Government. The constructive comments on SS's doctoral dissertation, a part of which is the present paper, by Profs. Y. Masumoto, Y. N. Takayabu, M. Watanabe and H. Miura (University of Tokyo) and discussions with Profs. B. Taguchi (University of Toyama), K. Nishii (Mie University) and Dr. M. Mori (Kyushu University) have been helpful in carrying out this research. The authors also thank Dr. H. Hendon (Bureau of Meteorology), Prof. M. Reeder (Monash University) and their colleagues for useful discussions and allowing to access some local data.

\section{Data Availability Statement}

Australian rainfall datasets are obtained from the Australian Bureau of Meteorology (http://www.bom. gov.au/climate/data-services/). The JRA-55 reanalysis datasets are provided by Japan Meteorological Agency (https://jra.kishou.go.jp/JRA-55/index_en.html), HadISST data by Met Office Hadley Centre (http://www. metoffice.gov.uk/hadobs/hadisst/), ORA-S5 datasets by ECMWF (https://www.ecmwf.int/en/research/ climate-reanalysis/ocean-reanalysis). NCAR Command Language (http://dx.doi.org/10.5065/D6WD3 XH5) version 6.5.0 has been used for the analyses and visualizations.

\section{REFERENCES}

Ashok, K., S. K. Behera, S. A. Rao, H. Weng, and T. Yamagata, 2007: El Niño Modoki and its possible teleconnection. J. Geophys. Res., 112, C11007, https://doi.org/10.1029/2006JC003798.

, Z. Guan, and T. Yamagata, 2003: Influence of the Indian Ocean Dipole on the Australian winter rainfall, Geophys. Res. Lett., 30, 1821, https://doi.org/10.1029/2003GL017926.

Berry, G., M. J. Reeder, and C. Jakob, 2011: Physical mechanisms regulating summertime rainfall over northwestern Australia, J. Climate, 24, 3705-3717, https://doi.org/10.1175/2011JCLI3943.1.

Bowman, D., 2002: The Australian summer monsoon: a biogeographic perspective. Australian Geographical Studies, 40, 261-277. https://doi. org/10.1111/1467-8470.00179.

Bretherton, C. S., M. E. Peters, and L. E. Back, 2004: Relationships between water vapor path and precipitation over the tropical oceans, J. Climate, 17, 1517-1528, https://doi.org/10.1175/15200442(2004)017<1517:RBWVPA>2.0.CO;2.

Cai, W., P. van Rensch, T. Cowan, and A. Sullivan, 2010: Asymmetry in ENSO teleconnection with regional rainfall, its multidecadal variability, and impact. J. Climate, 23, 4944-4955, http://doi.org/ 10.1175/2010JCLI3501.1.

and H. H. Hendon, 2011: Teleconnection pathways of ENSO and the IOD and the mechanisms for impacts on Australian rainfall, J. Climate, 24, 3910-3923, https://doi.org/10.1175/2011JCLI4129.1.

Craig, G. C., and S. L. Gray, 1996: CISK or WISHE as the mechanism for tropical cyclone intensification. J. Atmos. Sci., 53, 3528-3540, https://doi.org/ 10.1175/1520-0469(1996)053<3528:COWATM> 2.0.CO;2.

Drosdowsky, W., 1996: Variability of the Australian summer monsoon at Darwin: 1957-1992. J. Climate, 9, 85-96, http://doi.org/10.1175/15200442(1996)009<0085:VOTASM>2.0.CO;2.

, and M. Williams, 1991: The Southern Oscillation in the Australian region. Part I: Anomalies at the extremes of the oscillation. $J$. Climate, 4, 619-638, http://doi.org/10.1175/ 1520-0442(1991)004<0619:TSOITA>2.0.CO;2. 
Du, Y., T. Qu, G. Meyers, Y. Masumoto, and H. Sasaki, 2005: Seasonal heat budget in the mixed layer of the southeastern tropical Indian Ocean in a highresolution ocean general circulation model. $J$. Geophys. Res., 110, C04012, https://doi.org/ 10.1029/2004JC002845.

Emanuel, K. A., 1987: An air-sea interaction model of intraseasonal oscillations in the tropics. J. Atmos. Sci., 44, 2324-2340, https://doi.org/10.1175/15200469(1987)044<2324:AASIMO>2.0.CO;2.

J. D. Neelin, and C. S. Bretherton, 1994: On large-scale circulations in convecting atmospheres. Quart. J. Roy. Meteor. Soc., 120, 1111-1143, https://doi.org/10.1002/qj.49712051902.

Evans, S., R. Marchand, and T. Ackerman, 2014: Variability of the Australian monsoon and precipitation trends at Darwin. J. Climate, 27, 8487-8500, http://doi.org/10.1175/JCLI-D-1300422.1

Frost, A. J., A. Ramchurn, and A. Smith, 2018: The Australian landscape water balance model (AWRA-L v6). Technical description of the Australian water resources assessment landscape model version 6, http://www.bom.gov.au/water/ landscape/assets/static/publications/AWRALv6_ Model_Description_Report.pdf.

Gill, A. E., 1980: Some simple solutions for heatinduced tropical circulation. Quart. J. Roy. Meteor. Soc., 106, 447-462, http://doi.org/10.1002/qj. 49710644905.

Heidemann, H., J. Ribbe, T. Cowan, B. J. Henley, C. Pudmenzky, R. Stone, and D. H. Cobon, 2022: The influence of interannual and decadal Indo-Pacific sea surface temperature variability on Australian monsoon rainfall, J. Climate, 35, 425-444, https://doi.org/10.1175/JCLI-D-21-0264.1.

Hendon, H. H., and B. Liebmann, 1990a: A composite study of onset of the Australian summer monsoon, J. Atmos. Sci., 47, 2227-2240, http://doi.org/ 10.1175/1520-0469(1990)047<2227:ACSOOO> 2.0.CO;2.

, and 1990b: The intraseasonal (30-50 day) oscillation of the Australian summer monsoon. J. Atmos. Sci., 47, 2909-2923, http://doi.org/10.1175/1520-0469(1990)047<29 09:TIDOOT>2.0.CO;2.

E.-P. Lim, and G. Liu, 2012: The role of airsea interaction for prediction of Australian summer monsoon rainfall. J. Climate, 25, 12781290, http://doi.org/10.1175/JCLI-D-11-00125.1.

Holland, G. J., 1986: Interannual variability of the Australian summer monsoon at Darwin: 1952-82. Mon. Wea. Rev., 114, 594-604, http://doi.org/

\subsection{5/1520-0493(1986)114<0594:IVOTAS>} 2.0.CO;2.

Holloway, C. E., and J. D. Neelin, 2009: Moisture vertical structure, column water vapor, and tropical deep convection, J. Atmos. Sci., 66, 16651683, https://doi.org/10.1175/2008JAS2806.1.

Howden S. M., S. J. Crimp, C. J. Stokes, 2008: Climate change and Australian livestock systems: impacts, research and policy issues. Australian Journal of Experimental Agriculture, 48, 780-788, https://doi. org/10.1071/EA08033.

Inoue, K. and L. Back, 2015: Column-integrated moist static energy budget analysis on various time scales during TOGA COARE. J. Atmos. Sci., 72, 1856-1871, https://doi.org/10.1175/JAS-D-140249.1 .

Jones, D., W. Wang, and R. Fawcett, 2009: Highquality spatial climate data-sets for Australia. Australian Meteor. Ocean. J., 58, 233-248, http://doi.org/10.22499/2.5804.003.

Kajikawa, Y., B. Wang, and J. Yang, 2010: A multitime scale Australian monsoon index. Int. J. Climatol., 30, 1114-1120, http://doi.org/10.1002/ joc. 1955.

Kalnay, E., M. Kanamitsu, R. Kistler, W. Collins, D. Deaven, L. Gandin, M. Iredell, S. Saha, G. White, J. Woollen, Y. Zhu, M. Chelliah, W. Ebisuzaki, W. Higgins, J. Janowiak, K.C. Mo, C. Ropelewski, A. Leetmaa, R. Reynolds, and R. Jenne, 1996: The NCEP/NCAR 40-year reanalysis project. Bull. Amer. Meteor. Soc., 77, 437-471, https://doi.org/ 10.1175/1520-0477(1996)077<0437:TNYRP>2.0. $\mathrm{CO} ; 2$.

Kawamura, R., Y. Fukuta, H. Ueda, T. Matsuura, and S. Iizuka, 2002: A mechanism of the onset of the Australian summer monsoon, J. Geophys. Res., 107, http://doi.org/10.1029/2001JD001070.

Kim, S.-B., I. Fukumori, and T. Lee, 2006: The closure of the ocean mixed layer temperature budget using level-coordinate model fields. J. Atmos. Ocean. Technol., 23, 840-853, https://doi.org/10.1175/ JTECH1883.1.

Kobayashi, S., Y. Ota, Y. Harada, A. Ebita, M. Moriya, H. Onoda, K. Onogi, H. Kamahori, C. Kobayashi, H. Endo, K. Miyaoka, and K. Takahashi, 2015: The JRA-55 Reanalysis: General specifications and basic characteristics. J. Meteor. Soc. Japan, 93, 5-48, http://doi.org/10.2151/jmsj.2015-001.

Larkin, N. K., and D. E. Harrison, 2002: ENSO warm (El Niño) and cold (La Niña) event life cycles: ocean surface anomaly patterns, their symmetries, asymmetries, and implications. J. Climate, 15, 
1118-1140, http://doi.org/10.1175/1520-0442 (2002)015<1118:EWENOA>2.0.CO;2.

Lo, F., M. C. Wheeler, H. Meinke, and A. Donald, 2007: Probabilistic forecasts of the onset of the north Australian wet season, Mon. Wea. Rev., 135, 3506-3520, https://doi.org/10.1175/MWR3473.1.

Martius, O., K. Wehrli, and M. Rohrer, 2021: Local and remote atmospheric responses to soil moisture anomalies in Australia, J. Climate, 34, 9115-9131, https://doi.org/10.1175/JCLI-D-21-0130.1.

Matsuno, T., 1966: Quasi-geostrophic motions in the equatorial area. J. Meteor. Soc. Japan., 44, 25-43, https://doi.org/10.2151/jmsj1965.44.1_25.

Meehl, G. A., 1987: The annual cycle and interannual variability in the tropical Pacific and Indian Ocean regions. Mon. Wea. Rev., 115, 27-50, http://doi.org/10.1175/1520-0493(1987)115 $<0027$ :TACAIV>2.0.CO;2.

Mitchell, T. P., and J. M. Wallace, 1992: The annual cycle in equatorial convection and sea surface temperature. J. Climate, 5, 1140-1156, http://doi.org/10.1175/1520-0442(1992)005 <1140:TACIEC>2.0.CO;2.

Mollah, W. S., and I. M. Cook, 1996: Rainfall variability and agriculture in the semi-arid tropics - the Northern Territory, Australia, Agricultural and Forest Meteor., 79, 39-60, https://doi.org/10.1016/0168-1923(95)02267-8.

Narsey, S., M. J. Reeder, D. Ackerley, and C. Jakob, 2017: A midlatitude influence on Australian monsoon bursts, J. Climate, 30, 5377-5393, https://doi.org/10.1175/JCLI-D-16-0686.1.

Neelin, J. D., and I. M. Held, 1987: Modeling tropical convergence based on the moist static energy budget. Mon. Wea. Rev., 115, 3-12, https://doi.org/10.1175/1520-0493(1987)115 <0003:MTCBOT>2.0.CO;2.

Ooyama, K. V., 1982: Conceptual evolution of the theory and modeling of the tropical cyclone. $J$. Meteor. Soc. Japan, 60, 369-380, https://doi.org/ 10.2151/jmsj1965.60.1_369.

Paulson, C. A., and J. J. Simpson, 1977: Irradiance measurements in the upper ocean. J. Phys. Oceanogr., 7, 952-956, https://doi.org/10.1175/ 1520-0485(1977)007<0952:IMITUO>2.0.CO;2.

Power, S., T. Casey, C. Folland, A. Colman, and V. Mehta, 1999: Inter-decadal modulation of the impact of ENSO on Australia. Climate Dyn., 15, 319-324, https://doi.org/10.1007/s003820050284.

Raymond, D. J., S. L. Sessions, A. H. Sobel, and Ž. Fuchs, 2009: The mechanics of Gross Moist
Stability. J. Adv. Model. Earth Syst., 1, 9, https://doi.org/10.3894/JAMES.2009.1.9.

Rayner, N. A., D. E. Parker, E. B. Horton, C. K. Folland, L. V. Alexander, D. P. Rowell, E. C. Kent, and A. Kaplan, 2003: Global analyses of sea surface temperature, sea ice, and night marine air temperature since the late nineteenth century. $J$. Geophys. Res., 108, 4407, http://doi.org/10.1029/ 2002JD002670.

Risbey, J. S., M. J. Pook, P. C. Mcintosh, M. C. Wheeler, and H. H. Hendon, 2009: On the remote drivers of rainfall variability in Australia. Mon. Wea. Rev., 137, 3233-3253, http://doi.org/ 10.1175/2009MWR2861.1.

Saji, N. H., B. N. Goswami, P. N. Vinayachandran, and T. Yamagata, 1999: A dipole in the tropical Indian Ocean. Nature, 401, 360-363, http://doi.org/ $10.1038 / 43854$.

Sasaki H., M. Nonaka, Y. Masumoto, Y. Sasai, H. Uehara, and H. Sakuma, 2008: An eddy-resolving hindcast simulation of the quasiglobal ocean from 1950 to 2003 on the Earth Simulator. In: Hamilton K., Ohfuchi W. (eds) High Resolution Numerical Modelling of the Atmosphere and Ocean. Springer, New York, NY. https://doi.org/10.1007/978-0387-49791-4_10.

Sekizawa, S., H. Nakamura, and Y. Kosaka, 2018: Interannual variability of the Australian summer monsoon system internally sustained through wind-evaporation feedback. Geophys. Res. Lett., 45, 7748-7755, http://doi.org/10.1029/2018GL 078536.

, and

2021:

Remote influence of the interannual variability of the Australian summer monsoon on wintertime climate in East Asia and the western North Pacific, J. Climate, 34, 9551-9570, https://doi.org/ 10.1175/JCLI-D-21-0202.1.

Sharmila, S., and H. H. Hendon, 2020: Mechanisms of multiyear variations of northern Australia wetseason rainfall. Sci. Rep., 10, 5086, http://doi. org/10.1038/s41598-020-61482-5.

Suppiah, R., 1992: The Australian summer monsoon: a review. Prog. Phys. Geogr.: Earth and Environment,16, 283-318, http://doi.org/10.1177/ 030913339201600302.

Watanabe, M., and M. Kimoto, 2000: Atmosphereocean thermal coupling in the North Atlantic: A positive feedback. Quart. J. Roy. Meteor. Soc., 126, 3343-3369, https://doi.org/10.1002/qj.497126570 17.

Wheeler, M. C., H. H. Hendon, S. Cleland, H. Meinke, and A. Donald, 2009: Impacts of the Madden- 
Julian Oscillation on Australian rainfall and circulation. J. Climate, 22, 1482-1498, http://doi.org/10.1175/2008JCLI2595.1.

Xie, S.-P., and S. G. H. Philander, 1994: A coupled ocean-atmosphere model of relevance to the ITCZ in the eastern Pacific. Tellus A, 46, 340-350, http://doi.org/10.3402/tellusa.v46i4.15484.

Yanai, M., S. Esbensen, and J. Chu, 1973: Determination of bulk properties of tropical cloud clusters from large-scale heat and moisture budgets. J. Atmos. Sci., 30, 611-627, https://doi. org/10.1175/1520-0469(1973)030<0611:DOBPO $\mathrm{T}>2.0 . \mathrm{CO} ; 2$.

Zhang, B., R. J. Kramer, and B. J. Soden, 2019: Radiative feedbacks associated with the MaddenJulian Oscillation, J. Climate, 32, 7055-7065, https://doi.org/10.1175/JCLI-D-19-0144.1.

Zuo, H., M. A. Balmaseda, S. Tietsche, K. Mogensen, and M. Mayer, 2019: The ECMWF operational ensemble reanalysis-analysis system for ocean and sea ice: a description of the system and assessment, Ocean Sci., 15, 779-808, https://doi.org/10.5194/os-15-779-2019. 


\section{Supplemental figures}

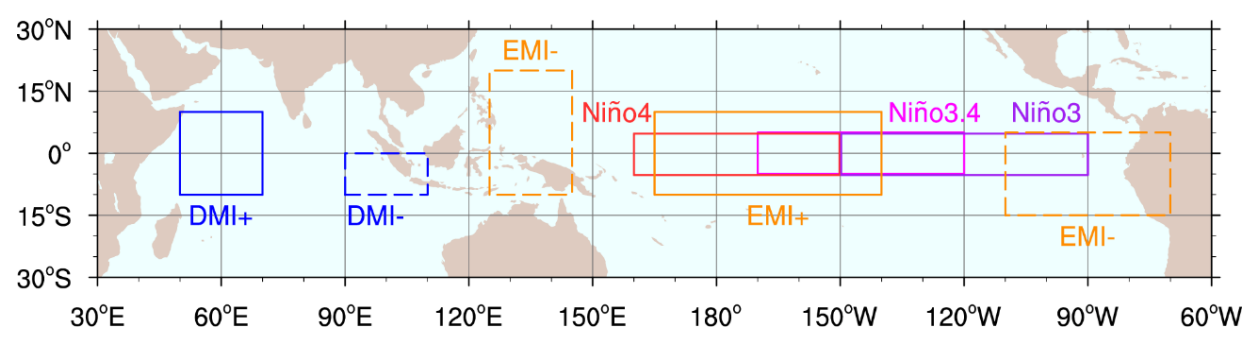

Fig. S1. Domains for the definitions of tropical SST indices. Purple, magenta, red, orange and blue boxes denote the domains for Niño3, Niño3.4, Niño4, EMI and DMI, respectively. SST anomalies in solid and dashed rectangles contribute positively and negatively, respectively, to the corresponding indices. Let $x(A)$ be SST anomaly averaged over domain $A$, these indices are defined as the following:

$\mathrm{Niño3}$ index $=x\left(5^{\circ} \mathrm{S}-5^{\circ} \mathrm{N}, 150^{\circ}-90^{\circ} \mathrm{W}\right)$

Niño3.4 index $=x\left(5^{\circ} \mathrm{S}-5^{\circ} \mathrm{N}, 170^{\circ}-120^{\circ} \mathrm{W}\right)$

Niño4 index $=x\left(5^{\circ} \mathrm{S}-5^{\circ} \mathrm{N}, 160^{\circ} \mathrm{E}-150^{\circ} \mathrm{W}\right)$

$\mathrm{EMI}=x\left(10^{\circ} \mathrm{S}-10^{\circ} \mathrm{N}, 165^{\circ} \mathrm{E}-140^{\circ} \mathrm{W}\right)-0.5 \times x\left(10^{\circ} \mathrm{S}-20^{\circ} \mathrm{N}, 125^{\circ}-145^{\circ} \mathrm{E}\right)$

$$
-0.5 \times x\left(15^{\circ} \mathrm{S}-5^{\circ} \mathrm{N}, 110^{\circ}-70^{\circ} \mathrm{W}\right)
$$

$\mathrm{DMI}=x\left(10^{\circ} \mathrm{S}-10^{\circ} \mathrm{N}, 50^{\circ}-70^{\circ} \mathrm{E}\right)-x\left(10^{\circ} \mathrm{S}-\mathrm{EQ}, 90-110^{\circ} \mathrm{E}\right)$. 


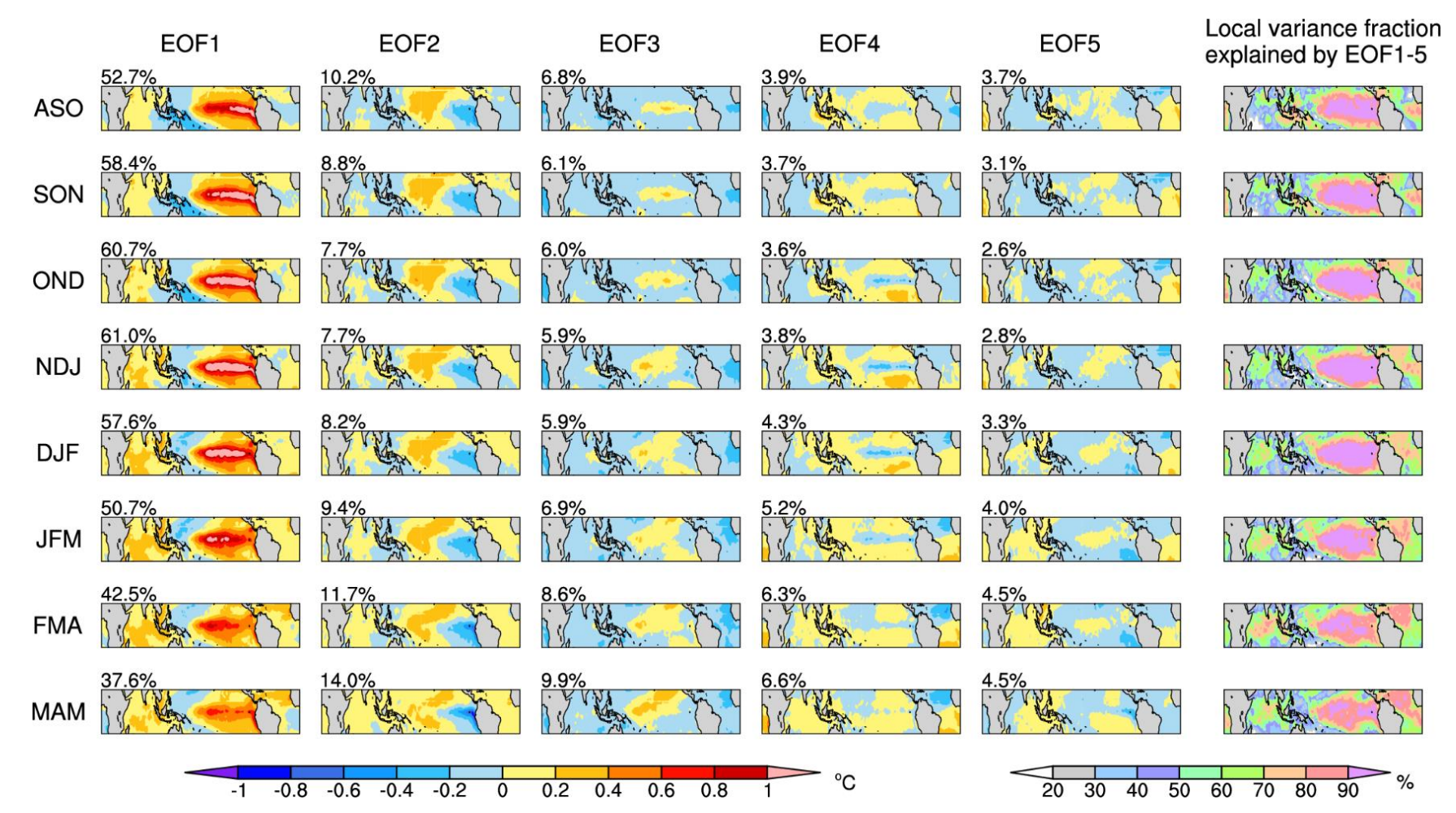

Fig. S2. (From left to right) The first to fifth EOFs of three month-mean SST over $20^{\circ} \mathrm{S}-20^{\circ} \mathrm{N}$ (left color bar) and local variance fraction explained by these five EOFs (right color bar) based on HadISST (1958-2021). 
This manuscript is a preprint submitted to EarthArXiv and not yet peer-reviewed

(a) Q'

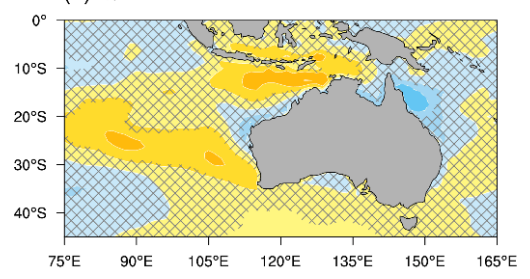

(c) Q' (SST term)

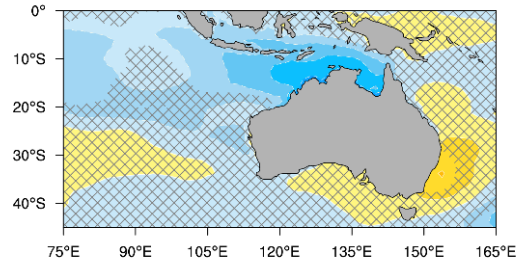

(b) Q' (Wind speed term)

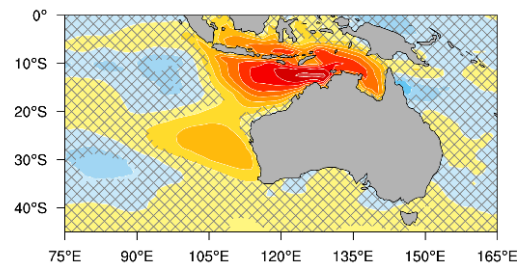

(d) Q' (Humidity term)

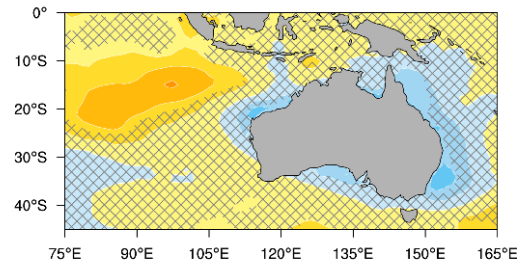

$\mathrm{W} / \mathrm{m}^{2}$

Fig. S3. (a) JF-mean surface LHF anomalies regressed onto the AUSM index. (b-d) Same as in (a) but for individual contributions from anomalies in (b) surface wind speed, (c) SST and (d) surface specific humidity, based on JRA-55 (1958-2021). Areas with significance below the 95\% confidence level are hatched. See Sekizawa et al. (2018) for detail. 